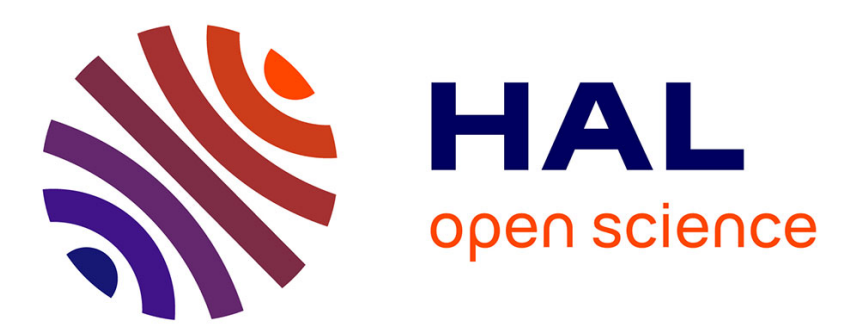

\title{
Design for human safety in manufacturing systems: applications of design theories, methodologies, tools and techniques
}

\author{
Leyla Sadeghi, Jean-Yves Dantan, Ali Siadat, Jacques Marsot
}

\section{To cite this version:}

Leyla Sadeghi, Jean-Yves Dantan, Ali Siadat, Jacques Marsot. Design for human safety in manufacturing systems: applications of design theories, methodologies, tools and techniques. Journal of Engineering Design, 2016, 27 (12), pp.844-877. 10.1080/09544828.2016.1235262 . hal-01394720

\author{
HAL Id: hal-01394720 \\ https://hal.science/hal-01394720
}

Submitted on 9 Nov 2016

HAL is a multi-disciplinary open access archive for the deposit and dissemination of scientific research documents, whether they are published or not. The documents may come from teaching and research institutions in France or abroad, or from public or private research centers.
L'archive ouverte pluridisciplinaire HAL, est destinée au dépôt et à la diffusion de documents scientifiques de niveau recherche, publiés ou non, émanant des établissements d'enseignement et de recherche français ou étrangers, des laboratoires publics ou privés. 


\title{
Design for human safety in manufacturing systems: applications of design theories, methodologies, tools and techniques
}

\author{
Leyla Sadeghi $^{\mathrm{a}}$, Jean-Yves Dantan ${ }^{\mathrm{a}}$, Ali Siadat $^{\mathrm{a}}$ and Jacques Marsot ${ }^{\mathrm{b}}$ \\ a Laboratory of Design, Manufacturing and Control (LCFC), Arts et Métiers ParisTech, Metz, \\ France; ${ }^{\mathrm{b}}$ French National Research and Safety Institute (INRS), Vandoeuvre-les-Nancy, France
}

\begin{abstract}
During recent decades, there has been growing awareness of human safety in the design process. The purpose of this paper is to review the literature on design for human safety (DfHS) in manufacturing systems. To this end, a process for systematically reviewing DfHS studies was used. The authors focused in particular on the applications of design theories and methodologies (DTM) and design tools and techniques (DTT) to analyse and identify work situations in order to improve human safety in manufacturing system design. The authors also tried to identify the design phases in which these DTM and DTT could be applied. This research review covered papers published between 1980 and 2015, and combined seven groups of terms: DfHS, design, safety, DTM, DTT, risk and working situation. A critical analysis was also performed in view to defining a research agenda and the most prominent key actions capable of pointing out paths for future research.
\end{abstract}

\section{Introduction}

Concurrent engineering (CE) is an approach for improving quality, reducing costs, compressing cycle times, increasing flexibility, raising productivity and efficiency, and improving social image in product development (Huang 1996). To implement CE, design for $X$ (DfX) is one of the most effective approaches (Chiu and Okudan 2010; Holt and Barnes 2010; Huang 1996). This approach, which includes design for manufacturing (Dixon and Poli 1995; Kuo, Huang, and Zhang 2001), design for assembly (e.g. Boothroyd and Dewhurst 1983), design for recycling/disposal (e.g. Alting and Jøgensen 1993; Zhang, Kuo, and Lu 1997), design for quality (Nepal, Monplaisir, and Singh 2006) and design for safety (DfS) (e.g. Duijne et al. 2007; Ghemraoui, Mathieu, and Tricot 2009a, 2009b; Sadeghi et al. 2013a, $2013 b)$, is employed to improve product design as well as the design process from the specific perspective represented by X (Huang 1996). The aim of DfX is to make the product better suited for the life phases it will undergo, and increase the general virtues of the product in order to improve product performance (Huang 1996). According to van Hemel and Keldman (1996) and Holt and Barnes (2010), X represents: 
- A specific property (e.g. cost, quality, lead time, efficiency, flexibility, safety, risk or environmental effects) and

- A life-cycle phase of the product (e.g. manufacturing, assembly, distribution, service or discarding).

Designers of manufacturing systems have also been obliged to satisfy essential safety and health requirements since the so-called Machinery directive came into force at the end of the 1980s. According to European Directive 89/392/EEC (European Commission 1989):

Machinery must be so constructed that it is fitted for its function, and can be adjusted and maintained without putting persons at risk when these operations are carried out under the conditions foreseen by the manufacturer. The aim of the measures taken must be to eliminate any risk of accident throughout the foreseeable lifetime of the machinery, including the phases of assembly and dismantling, even where risks of accident arise from foreseeable abnormal situations.

The integration of safety in the design process is considered more as a constraint to comply with European directives 2006/42/EC (European Commission 2006) (new version). Therefore, interest in the concept of safety integration from the earliest design phases is growing rapidly.

This research addresses safety and thus DfS. Safety can concern product safety and human safety. Even though it has not been highlighted in the literature, it is significant that the distinction between product safety and human safety is rather vague. Product safety addresses the quality of a product and its utilisation without risk (Rausand and Utne 2009), whereas human safety concerns accident prevention in work situations (Sadeghi et al. 2015). These definitions are a little vague and imprecise. For example, human safety can be related to the risk of human entanglement with a rotating element, whereas design for product safety (DfPS), for example, can be related to the non-functioning of a system or part of a system under given conditions for a given time. It should be mentioned that product safety also impacts on human safety (Rausand and Utne 2009). For example, a person is at an increased risk of having an accident if they are in the vicinity of a power take-off driveshaft system with a broken or damaged safeguard. In fact, in the case of a broken or damaged safeguard of the system, this system is very dangerous. It should be pointed out that in the manufacturing context, the 'process safety' (Khan, Rathnayaka, and Ahmed 2015) concept has been used. However, this paper just limited in human safety related to product utilisation and its behaviour. In other words, consequences of lean production for worker's health and safety focusing on effects on psychosocial factors and musculoskeletal disorders were not in scope of this paper.

This overview focuses on human safety, which gives rise to the question of the difference between design for human safety (DfHS) and other DfX approaches. Generally, the answer to this question is simple. DfX are linked to a system and its structure, whereas DfHS is linked to human-machine interaction. Consequently, designers tend to use tools and techniques that focus on the product and its utilisation. Therefore, in the DfHS context, the object of the study differs in comparison to other DfX approaches. Human-machine interaction has effects on human health and safety. It should be noted that this paper addresses only the aspect of human safety. In other words, the impact of human performance on health is not considered. Human safety concerns accident prevention in work situations. These accidents are related not only to normal operating conditions, but also to 'foreseeable 
abnormal situations' as defined by the Machinery Directive. To achieve this, designers must increase their knowledge on how systems perform during use. This means that designers have greater scope and motivation to learn from experience of systems in use to improve safety. These concepts will be explained in more detail in the course of this paper.

The term DfHS captures this effort to integrate knowledge of human safety in the design process (Sadeghi et al. 2013a). Integrating human safety in the design process is a very complex issue because of the variability of its main components: human beings, machines and their environment, as well as the variability of possible interactions between these components.

The purpose of this paper is to review the literature on DfHS in manufacturing systems. The large number of studies that include a wide range of topics makes it difficult to provide stakeholders with an overview of this field. The authors looked in particular for the applications of design theories and methodologies (DTM) and design tools and techniques (DTT) to analyse and identify work situations in order to improve human safety in manufacturing systems. One question that must be answered is: Which research studies have used DTM and DTT in the context of DfHS? This is our main research issue. More precisely, in this paper, we address the following question: How can work situations be identified and analysed using these DMT and DTT?

For more information on different DTM and/or DTT, the reader can refer to Andreasen (2011), Kroll (2013), Le Masson, Dorst, and Subrahmanian (2013), Lutters et al. (2014) and Tomiyama et al. (2009). These papers classified or provided an overview of DTM and/or DTT.

Nowadays, one of the most common modes of reasoning taught and used in product design is the systematic design approach proposed by Pahl and Beitz. In a general way, the term systematic design refers to a set of theories and methods that include abstraction to identify the essential problems, establishing function structure, searching for solution principles, combining solution principles, etc. These specific techniques contribute to a design process based on different ways of describing the product to be designed, such as the three phases mentioned by Pahl and Beitz (Pahl et al. 2007):

(1) Conceptual design allows abstracting the essential problems, establishing function structures, searching for suitable working principles and combining them into a working structure. This leads to the specification of principles or concepts.

(2) Embodiment design allows formulating a concept and determining the structure (overall layout) of a technical system in line with technical and economic criteria.

(3) Detailed design allows defining the arrangement, forms, dimensions and surface properties of the individual parts.

DTT and DTM can be interrelated at different phases of the design process. Not all DTT and DTM can be used in DfHS, but for those that can, it is interesting to try to identify the design phase(s) in which they could be applied.

The remainder of this study is structured as follows. In Section 2, the framework of this systematic review of DfHS studies is described. Section 3 reviews the literature for available research based on DTM for considering safety in the design process. Section 4 discusses DTT to improve safety. Section 5 provides a discussion on the chronological and thematic perspectives, proposes two main research findings and identifies three research gaps and the corresponding agendas. Finally, the conclusions are given in Section 6. 


\section{Research methodology}

This section explains the framework of our review on DfHS. To this end, we first present a brief overview of existing reviews on DfHS after which the contributions of present review are presented and contrasted against past reviews.

\subsection{Literature reviews on DfHS}

The large number of designs for human safety studies covering a wide variety of topics (Duijne et al. 2007; Ghemraoui, Mathieu, and Tricot 2009a, 2009b; Hasan et al. 2003; Houssin and Coulibaly 2011; Marsot and Claudon 2004; Sadeghi et al. 2013a, 2013b) makes it difficult for stakeholders to obtain a comprehensive overview of this field. Hence, a systematic review of previous studies is paramount for facilitating sharing useful research findings and identifying future trends in DfHS research. Several literature reviews on safety considerations in design have already been published, for example:

- Kjellén and Sklet (1995) reviewed different risk analysis methods used to estimate the risk (probability/consequence) of occupational accidents on the basis of theoretical analysis.

- Fadier and Ciccotelli (1999) carried out a survey on available methods and models for integrating safety in the design process. They classified research and studies on design into three complementary categories: (1) design methods, (2) design approaches/processes/models and (3) design paradigms and reasoning.

- Sklet (2006) reviewed the literature on safety barriers and how this concept and similar concepts are interpreted and used in industries. He addressed definitions and understanding of what a safety barrier is, a classification of safety barriers, and attributes of importance for the performance of safety barriers.

- Hale and Borys (2013) explored safety rules and procedures used at the workplace level in organisations.

- Sousa, Almeida, and Dias (2014) implemented a critical review focusing on major paths of research in the field of occupational safety and health in the construction industry. Their review covered occupational safety and health research, organised in studies on understanding accidents, accident analysis studies, accident modelling studies, and occupational safety and health risk management.

Most of the previous reviews were focused on specific aspects of safety, rather than being comprehensive and systematic. In addition, these reviews did not investigate DTM and DTT. We explain the framework of our review in the next section.

\subsection{Framework of review: aim, scope, and research questions}

Safety is defined as the absence of unwanted events. Risk is defined as the possibility of something unwanted happening. Therefore, safety essentially means the absence of risk (Hollnagel 2008). Hollnagel believes that the best way to ensure a state of safety is either to prevent something unwanted from happening or to protect against its consequences (2008). He states that in order to ensure safety by preventing something from happening, i.e. through the elimination of risks, it is first necessary that the risks are known or can be 
made known. So safety and risk are inextricably linked concepts, since the presence of one induces the absence of the other.

As mentioned in the Introduction, DfHS is linked to human-machine interaction. In addition to developing tools and processes to implement the DfHS concept in view to mitigating safety risk, research is needed to understand how to account for human interaction with systems and their work environment during design. The ways in which workers approach, operate and view machines can have impacts on hazards. Designers tend to use tools and techniques focused on products when using the system. Thus, the object of the study in this context is rather different from other design for $x$ approaches. And there is a need to consider work and usage situations during DfHS.

Here, we introduce the concept of work situation. The work system is composed of the means and of one or several workers (person(s) performing one or more tasks within the work system) who act together to carry out one or several tasks in a work environment in accordance with the conditions set for carrying out the work task (Hasan et al. 2003).

This work situation becomes unsafe if one person is exposed to one or several hazards. A hazard is defined as any phenomenon capable of causing an injury or damage to the health of the user during his or her work in the work situation (European Committee for Standardization [CEN] 2010). The dangerous zone is defined as any zone inside and/or around a machine in which a person is exposed to a risk of injury or damage to health.

The exposure of a person is often the consequence of performing a task on or around the machine. The work situation includes the factors that may influence the achievement of tasks such as work organisation, the installation of each machine relative to another, the working environment around the machine and the division of tasks.

It should be noted that the information from work physiology, biomechanics and anthropometry related to the work situation and the usage situation must be considered in the design process. This information is made available by the principles of 'Human Factors and Ergonomics' a concept that includes the environmental, organisational and job factors, and the human and individual characteristics which influence behaviour at work.

Figure 1 shows the framework of our review on DfHS. Risk and work situation are two aspects which must be considered for human safety. Applying DTM and DTT help to integrate safety in the design process. The general principles of risk prevention in the work situation can be found through DTT.

The aim of the research presented in this paper was to identify, interpret and summarise the literature currently available on DfHS. In determining the scope of this study, the focus was on articles central and relevant to the implementation of DTM and DTT. An example of a publication clearly within the scope of this review is that of Ghemraoui, Mathieu, and Tricot (2009a) in which the author proposed a general suggestion for systematic risk identification and the integration of human safety in the early design phase through using axiomatic design (AD) theory.

Similarly, articles that deal with product safety associated with DTM and DTT were all considered relevant. This strict distinction was necessary to deal specifically with the concept of DfHS and DfPS. The authors are, however, aware of the many articles more widely associated with DfPS that, although they fall outside the focus of this initial review, may be transformed into a useful contribution to the DfHS research.

The review covered papers published between 1980 and 2015. It combined seven groups of terms - DfHS, design, safety, DTM, DTT, risk and work situation. It should be 


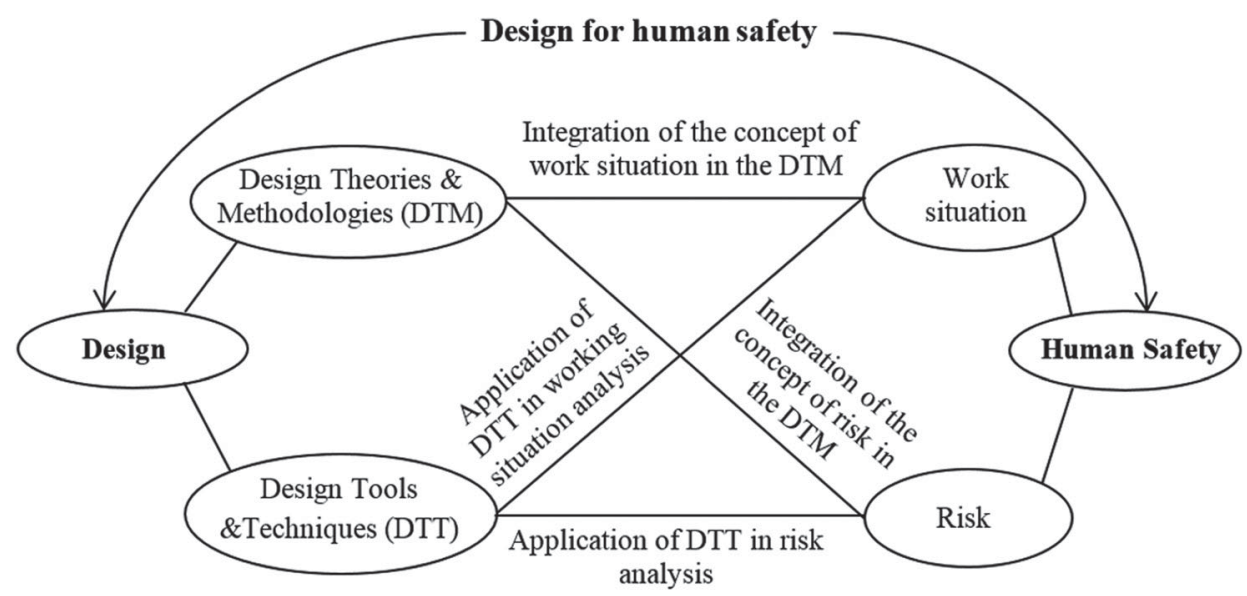

Figure 1. Framework of DfHS.

noted that this review focuses on the applications of DTM and DTT in manufacturing system DfHS.

In particular, the results of this study provide coverage of wider research which used DTM and DTT to improve human safety during the design process. The authors sought in particular to analyse and identify work situations. In terms of research questions, this review was approached on the basis of the following questions:

- What studies have used DTM and DTT in the context of DfHS?

- In which design phase(s) can these DTT and DTM be applied?

- How can the work situation be identified and analysed with these DMT and DTT?

- What are the strengths and weaknesses in the existing literature in terms of identifying and analysing work situations?

A systematic review is a specific and reproducible approach for identifying, selecting and appraising all the literature of a certain agreed level of quality and relevant to a research question. This study adopts the systematic review as a methodological approach in seven steps to review the existing DfHS literature to explore useful findings and identify knowledge gaps for future research. Figure 2 illustrates the main process of the systematic review conducted in this study.

The three steps of the literature search were aimed to collect enough appropriate publications related to DfHS research. The preliminary search in five databases led to the identification of 10 journals with the highest numbers of papers as target journals for secondary search. The results of the secondary search were used to select literature according to publication types and criteria. In the tertiary search, we did not limit the potential journals to cover a diverse range of publication formats including conference proceedings, theses and books.

In contrast to past reviews, the contributions of the present review are mainly based on two aspects: the coverage of wider research topics on DfHS, and the offering of systematic reviews on past, current and future research on DfHS. 


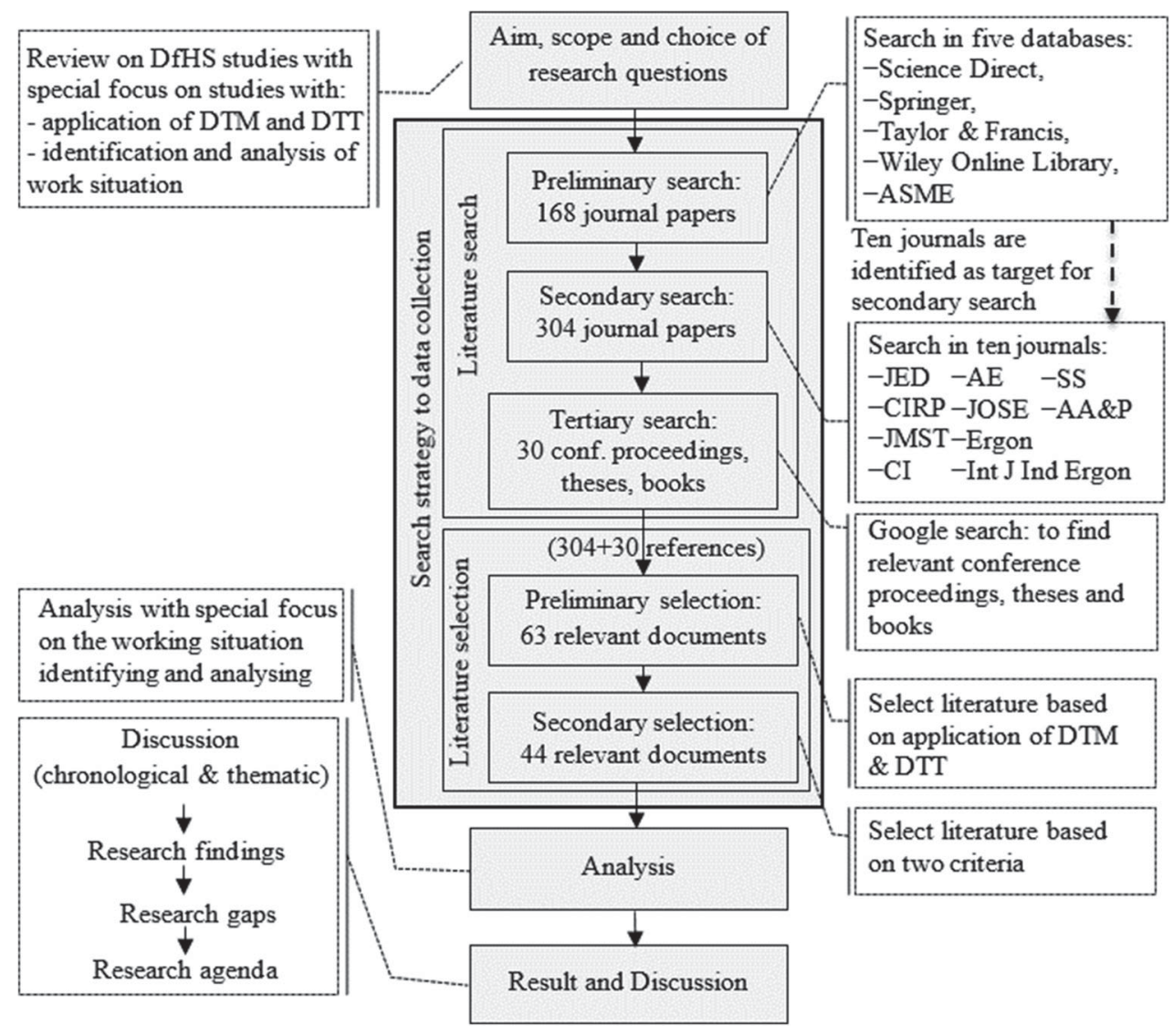

Figure 2. Process of systematic review on DfHS studies.

\subsection{Strategy of searching data collections}

\subsubsection{Literature search}

The aim of this step was to collect enough appropriate publications related to DfHS research. The search strategy was developed by first identifying the relevant time frame, data sources and key words. Initially, this study focused on literature published between 1980 and 2015, with their citations being cross-checked to ensure that any earlier publications were also captured. The preliminary search was conducted in five databases including Elsevier, Springer, Taylor \& Francis, Wiley Online Library, and American Society of Mechanical Engineers (ASME). The five databases involved the main peer-referred journals on the topic of DfHS.

In the preliminary search, a comprehensive and extensive search was implemented under the 'Title' field in the databases with the full search schema 'Title ((design) and (safety))'. Whereas, from preliminary search, many thousands of papers could be found, we tried to remove some of them. To this aim, we considered the papers which seem placed in the 'DfS' domain. In addition, we limited to papers in three following domains: 'engineering design', 'safety management' and 'ergonomics' (the papers in domain like food engineering or biology were not considered). For example, from a first screening in 'science 
Table 1. Preliminary search results in the five databases.

\begin{tabular}{|c|c|c|c|c|c|}
\hline Database searched & Science Direct & Springer & $\begin{array}{l}\text { Taylor \& } \\
\text { Francis }\end{array}$ & $\begin{array}{c}\text { Wiley Online } \\
\text { Library }\end{array}$ & ASME \\
\hline $\begin{array}{l}\text { Number of papers from first screening } \\
\text { With using the following full search schema: } \\
\text { 'Title ((design) and (safety))' }\end{array}$ & 441 & 378 & 463 & 158 & 183 \\
\hline $\begin{array}{l}\text { Number of papers from second screening } \\
\text { With removing the paper outside of three } \\
\text { following domains: 'engineering design', 'safety } \\
\text { management' and 'ergonomics' }\end{array}$ & 63 & 34 & 43 & 5 & 13 \\
\hline \multicolumn{6}{|c|}{ Total number of paper through preliminary search* in the five databases: 168} \\
\hline
\end{tabular}

Table 2. The number of relevant papers in the 10 journals and other publication formats.

\begin{tabular}{llcc}
\hline \multirow{2}{*}{ Field } & \multicolumn{1}{c}{$\begin{array}{c}\text { Journal title } \\
\text { Engineering design }\end{array}$} & $\begin{array}{c}\text { Abbreviated } \\
\text { journal title }\end{array}$ & $\begin{array}{c}\text { Number of } \\
\text { relevant papers }\end{array}$ \\
& $\begin{array}{l}\text { Journal of Engineering Design } \\
\text { CIRP Annals - Manufacturing Technology }\end{array}$ & JED & 4 \\
& CIRP Journal of Manufacturing Science \& Technology & CIRP & 1 \\
Safety management & Computers in Industry & $C I$ & 1 \\
& Safety Science & $S S$ & 5 \\
Ergonomics & Accident Analysis and Prevention & $A A \& P$ & 2 \\
& Applied Ergonomics & $A E$ & 4 \\
& International Journal of Occupational Safety and Ergonomics & JOSE & 2 \\
Others publication formats & Ergon & 2 \\
Total & Ergonomics & Int JInd Ergon & 3 \\
\hline
\end{tabular}

direct' database, 441 papers have been found but after a high level analysis of each paper's title, among these 441 papers, just 63 papers have been considered as preliminary search results. The following table have been added in in the revised manuscript. The preliminary search identified a total of 168 papers. Table 1 shows the preliminary search results in the five databases.

In order to ensure that the papers selected were of high quality, 10 journals with the highest numbers of papers focusing on DfHS were chosen (see Table 2). Four of these journals are leading journals in the field of 'engineering design'. Two of these journals are in the field of 'safety management'. The other four journals are also leading journals in the field of 'ergonomics'.

The secondary search within the 10 selected journals was implemented using the 'title/abstract/keyword' field of the databases. As none of the databases covered all the aforementioned journals, different databases had to be used. The search strategy initially identified keywords that could be associated with DfHS. The search was based on a range of combinations of the following keywords: design and safety or accident or hazard or risk. The secondary search identified a total of 304 papers.

Finally, we did not limit the potential journals to cover a diverse range of publication formats including conference proceedings, theses and books. To ensure completeness, an Internet search was also conducted using a similar process to that used with the library databases. The search was conducted using the same keywords in the secondary search. The results of these searches were combined to provide a total of 30 documents. 


\subsubsection{Literature selection}

The objective of this review was not to obtain a complete list of papers, but rather to explore the current trends, useful findings and research gaps of DfHS. On the other hand, some of the selected papers that did not match the subject but matched the research schema were selected. It was essential to make further efforts to screen and filter the 334 papers for indepth review. A preliminary review was conducted by reading the abstracts and keywords of the papers. The review selection was made on two levels. The preliminary selection of the papers was focused on the application of DTM and DTT in DfHS. After the preliminary selection, 63 relevant documents remained. In the secondary selection, two filter criteria were used to further select relevant papers for in-depth review and analysis: (1) the papers were focused on safety in domains other than design and manufacturing systems, for instance, construction safety (López-Arquillos, Rubio-Romero, and Martinez-Aires 2015) and (2) only the words in the search terms were mentioned, but not studied in depth. For example, Chinniah (2015) mentioned design in their abstract, but the paper focused on accident analysis.

After applying the selection criteria, 44 relevant documents remained. Table 2 gives the number of relevant papers in the 10 journals and other publication formats. Table 2 shows the distribution of the 26 papers in the 10 journals. Safety Science (SS) had the largest number of relevant papers, followed by the Journal of Engineering Design (JED) and Applied Ergonomics (AE). More than 50\% of the selected papers were published in these three journals, demonstrating the significance of JED, SS and AE in the area of DfHS research.

\subsection{Results and analysis}

Initially, the search terms identified some 334 journal articles, conference proceedings, theses and books, handbooks or reports. These were then carefully filtered to establish 41 documents that were directly relevant to our research enquiry. The literature review process generated the following two sections related to applying DTT and DTM in DfHS in manufacturing systems.

\section{DTM for human safety}

Design methodology is 'a concrete course of action for the design of technical systems that derives its knowledge from design science and cognitive psychology, and from practical experience in different domains' (Pahl et al. 2007). Some DTM are applied by designers to improve safety in the design of manufacturing systems.

Previous analysis demonstrated that DTM for human safety is applied by a range of studies. The research topics are wide ranging and diversified. As a result, four main groups of DfHS research surfaced. The first group involves the utilisation of 'theory of inventive problem solving' (TRIZ) in integrating safety in the design process. The second group mainly focuses on $A D$ theory to improve safety during the design process. The third one uses function-behaviour-structure (FBS) in DfHS. The fourth group pays attention to usability design and Kansei methodology to consider human factors in design. In the following, a brief description of these DTM and their applications in the context of DfHS is given. 


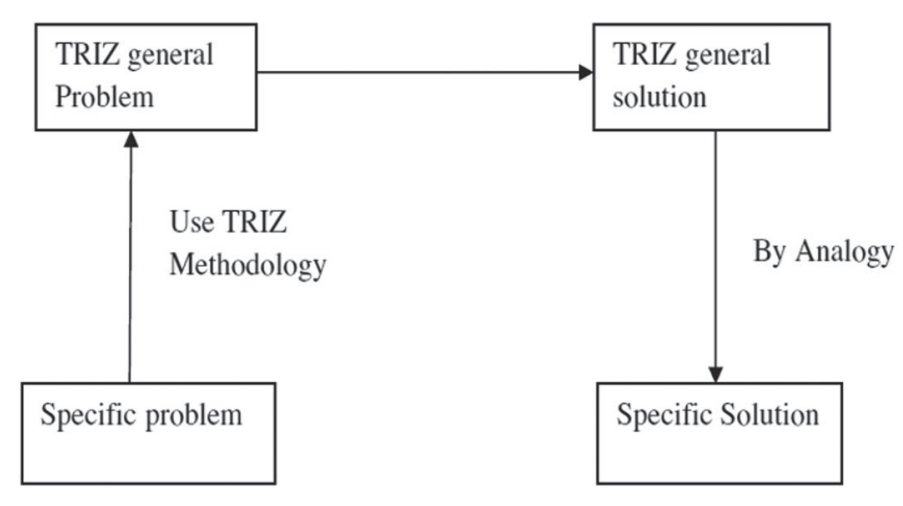

Figure 3. Approach for the TRIZ methodology.

\subsection{TRIZ in DfHS}

\subsubsection{Introduction to TRIZ}

The TRIZ proposed by Altshuller $(1984,1999)$ helps the designer to find solutions based on the analysis of the design problem and knowledge bases to solve design problems. Altshuller and his colleagues studied about 400,000 technology patents and from them identified certain regularities and basic patterns which govern problem-solving processes, the creation of new ideas and innovation. The approach used in the TRIZ methodology is shown in Figure 3.

It should be noted that TRIZ does not give the solutions but proposes paths for finding them. It is based on the basic idea of being able to generate several directions for the development of a new generation of products or processes. It uses different tools for formalising problems and resolving them. TRIZ involves contradictions, 40 inventive principles, a contradiction matrix, the ideal final result, scientific effects, ARIZ (Russian acronym for inventive problem-solving algorithm), substance-field analysis modelling and the laws of evolution.

\subsubsection{Literature review of TRIZ in DFHS}

In the literature, some papers have illustrated the applicability of TRIZ in DfHS. In the following, a brief description of these researches is given.

Marsot and Claudon (2004) proposed an approach based on TRIZ, functional analysis (FA) and quality function deployment (QFD) to integrate ergonomics in design. They proposed to use TRIZ to solve house of quality-highlighted compromises between certain functional parameters and ergonomic criteria. The FA and QFD will be explained in Section 4 which also explains DTM for human safety.

Hasan, Martin, and Bernard (2004) used the TRIZ contradiction matrix to solve contradictions related to the implementation of safety devices. In their study, safety is considered in contradiction with productivity. Their objective was to propose elements to pilot the emergence of new solutions concerning the resolution of contradictions related to integrating safety by using the work situation model. Hasan et al. showed the possibility of using the features and the inventive principles of contradiction to solve the safety problem.

Other authors (Houssin and Coulibaly 2011) have proposed an innovative approach aimed at eliminating these contradictions in order to improve product performance in work 
Table 3. Literature review of TRIZ in DfHS.

\begin{tabular}{|c|c|c|c|c|}
\hline Reference & Design phase & $\begin{array}{l}\text { Work situation } \\
\text { analysis }\end{array}$ & $\begin{array}{l}\text { Integration with other DTM } \\
\text { and DTT and techniques }\end{array}$ & Application \\
\hline $\begin{array}{l}\text { Marsot and } \\
\text { Claudon (2004) }\end{array}$ & $\begin{array}{l}\text { From conceptual } \\
\text { design }\end{array}$ & No & Functional analysis and QFD & Hand tool: boning knife \\
\hline $\begin{array}{l}\text { Hasan, Martin, and } \\
\text { Bernard (2004) }\end{array}$ & $\begin{array}{l}\text { From conceptual } \\
\text { design }\end{array}$ & Not explicit & - & No specific \\
\hline $\begin{array}{l}\text { Houssin and } \\
\text { Coulibaly (2011) }\end{array}$ & $\begin{array}{l}\text { From conceptual } \\
\text { design }\end{array}$ & Not explicit & - & Off-set printing line \\
\hline Sadeghi (2014) & $\begin{array}{l}\text { From conceptual } \\
\text { design }\end{array}$ & Not explicit & Systematic approach, AD, FTA & $\begin{array}{l}\text { Tractor power take-off } \\
\text { drive shaft }\end{array}$ \\
\hline
\end{tabular}

situations. Their approach is based on four steps: (1) systemic safety integration using a work situation model, (2) taking into account the requirements of safety directives and standards, (3) identifying the contradiction resulting from the designer's choices and, finally, (4) resolving these contradictions through TRIZ. TRIZ solves organisational problems by returning to the original problem of the technical system. They demonstrated the possibility of using the features and the inventive principles of contradiction to solve our safety problem.

To improve safety, Sadeghi (2014) proposed different safety objectives according to design phases. She believes that a safety objective can be expressed in one of three ways: (1) maximise a design parameter (e.g. maximise the distance between the operator and the rotating shaft), (2) minimise a design parameter (e.g. minimising the speed of rotation of the drive shaft) or (3) replace (or change) a design parameter (e.g. replace the rotating element with another safer element). Design consists of associating a solution with an objective. AD expresses the rules of good design through its two axioms (Suh 1990), but does not provide a clear description of how to reach a solution. In other words, AD allows defining problems and analysing solutions, but it does not generate ideas. On the other hand, TRIZ formalises design as a contradiction to be solved, i.e. it finds solutions by specifying the solution of a contradiction process. Thus, Sadeghi proposed using 11 principles of separation to meet the safety objective by replacing design parameters (DPs).

The results of this literature review of TRIZ in DfHS are shown in Table 3. These research works do not explicitly analyse work situations in their development.

\section{2. $A D$ in DfHS}

\subsubsection{Introduction to $A D$}

The AD theory was introduced by Suh in 1990. The goal of AD is to 'establish a scientific basis to improve design activities by providing the designer with a theoretical foundation based on logical and rational thought processes and tools' (Suh 2001). This theory consists of four fundamental concepts (Suh 1990, 2001).

Design as a mapping process. According to $A D$, design is made up of four domains (Figure 4). The customer domain is characterised by the needs that the customer is looking to satisfy in a product, process, system or materials. In the functional domain, the customer's needs are specified in terms of functional requirements (FRs) and constraints (Cs). In order to satisfy the specified FRs, DPs, which are the key variables, are conceived in the physical domain. Finally, to produce the product specified in terms of DPs, AD develops a procedure characterised by process variables in the process domain. 


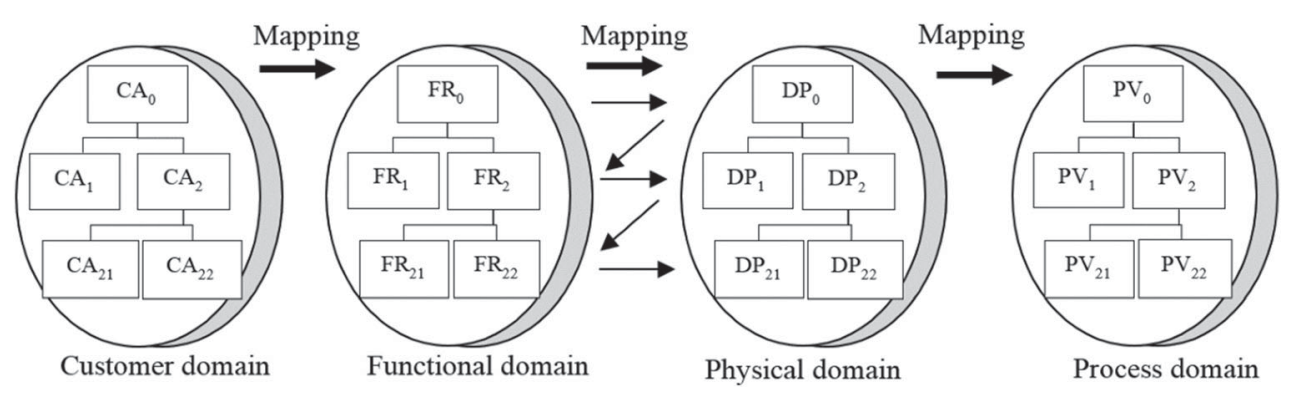

Figure 4. Axiomatic design.

Top-down hierarchical design structure. Design usually consists in decomposition with multiple abstraction levels. The higher levels are more abstract; the lower levels are more detailed. The design process has to begin at the system level and continue through more detailed levels until reaching a point of sufficient clarity to represent the design object (Figure 4). This process is called hierarchical decomposition and its outcome is depicted by a tree model in each of the four domains.

Design matrix. The relationship between FRs and DPs is represented in a matrix which allows evaluating the structure of the product. This matrix is called the 'design matrix' which links FRs to DPs and characterises the product design. When the design matrix is diagonal, the design is called an uncoupled design. The design is called a decoupled design when the design matrix is triangular. A coupled design occurs when the design matrix is a full matrix. Both uncoupled and decoupled designs satisfy the independence axiom and are considered acceptable in AD.

Design axioms. Suh formulated two axioms for good design: (1) the independence axiom: maintain the independence of the FR. In an acceptable design, mapping between the FRs and the DPs is such that each FR can be satisfied without affecting the other FRs; (2) the information axiom: minimise the information content of the design. If a set of designs satisfy the same FRs and conforms to the independence axiom, the best is that with the minimum information content. The information axiom provides a quantitative measure of the merits of a given design.

The reader is referred to Suh $(1990,2001)$ for further details on AD and its architecture.

\subsubsection{Literature review of $A D$ in DfHS}

In recent years, there have been attempts to apply AD principles in $\mathrm{DfHS}$. The integration of AD with other DTM or DTT, such as the systematic approach, has also appeared in the literature (Heo and Lee 2007; Ghemraoui, Mathieu, and Tricot 2009a; Sadeghi et al. 2013a, 2013b; Sadeghi 2014). In the following, a brief description of these research works is described.

An axiomatic approach to ergonomic design and a universal measure of system-human incompatibility were introduced by Karwowski (2005). Karwowski describes the rules of good ergonomic design which consists of human-design compatibility. The two axioms of $A D$ were adapted for ergonomic design purposes. Axiom 1 stipulates the independence of the functional compatibility requirements and axiom 2 stipulates the need to minimise the incompatibility content of the design. Ergonomic design is defined as mapping from system-human compatibility needs to relevant compatibility requirements. 
System-human compatibility is expressed in terms of human abilities and limitations at the beginning of the design process. Hazard prevention aspects are not taken into account.

Heo and Lee (2007) proposed a methodology to examine the design process using AD as a measure for evaluating safety. This is particularly important for identifying vulnerabilities and creating solutions. To improve performance and safety, various design strategies such as independency and redundancy were implemented. The authors suggested an alternative viewpoint for evaluating the deployment of design strategies in terms of AD theory. AD suggests two design principles and visualisation tools for organising the design process. The major benefit of $A D$ is that it is capable of providing suitable priorities for deploying design strategies. AD principles were used to develop the fault tree to analyse the reliability of the DPs used to meet the FRs.

Helander and his colleagues illustrated the applicability of AD principles in human factors design and human-computer interaction. Helander and Lin (2000) demonstrated the use of AD for the anthropometric design of workplaces. They showed how the formulation of FRs and DPs can help in conceptualising design principles and selecting DPs for a seated workplace. Their research suggested a new way of calculating the information contents in anthropometric design by redefining the concepts of system range and design range. Helander and Jiao (2002) suggested that the AD framework could be used to analyse and reduce coupling in software usability heuristics. To uncouple the design, a cluster analysis was performed on the original design matrix. FRs were then split and recombined in order to reduce the coupling. Helander (2007) and Lo and Helander (2007) extended previous efforts and developed a design equations for systems analysis methodology based on the principles of AD. The aim is to identify and suggest avenues for eliminating coupling between user goals and user actions. This methodology consists of four domains, namely user goals, FRs, DPs and user actions, to model the human-machine system functionally and structurally. However, this methodology describes the rules for achieving a usable design and then takes into account only the user action to meet a specific goal. Thus, it consists in performing a global analysis of solutions from the standpoints of design and usability.

To integrate safety systematically from the early design process, Ghemraoui, Mathieu, and Tricot (2009a, 2009b) first sought to formulate a systematic description of the design process. To this end, they used the 'extended axiomatic design' (EAD) proposed by Ge, Lu, and Suh (2002). EAD combines the systematic approach (Pahl et al. 2007) and AD (Suh $1990,2001)$. It consists in considering that three phases of the four phases of the systematic approach, i.e. conceptual, embodiment and detailed design, are divided into two domains: functional and physical. Ghemaroui et al. used the systematic approach to formulate a typology of safety objects at each design phase. To satisfy safety needs, they adopted a representation for the design process that links the systematic approach to AD theory (Suh 1990, 2001). The method proposed, innovative risk assessment design (IRAD), consists of a general suggestion for systematic risk identification and human-safety integration in the early design phase. It considers design as an iterative activity between a design process and a risk process. These two processes evolve simultaneously and influence each other. The design process is divided into six phases. Similarly, the risk process is divided into six contexts. This method consists of a general suggestion for systematic risk identification and human-safety integration in the early design phase. Consequently, IRAD considers design as an iterative activity between a design process and a risk process. 
Table 4. Literature review of AD in DfHS.

\begin{tabular}{|c|c|c|c|c|}
\hline Reference & Design phase & $\begin{array}{l}\text { Work situation } \\
\text { analysis }\end{array}$ & $\begin{array}{l}\text { Integration with other } \\
\text { DTM and DTT and } \\
\text { techniques }\end{array}$ & Application \\
\hline $\begin{array}{l}\text { Helander and Lin } \\
(2000)\end{array}$ & $\begin{array}{l}\text { From embodiment } \\
\text { design }\end{array}$ & Not explicit & - & $\begin{array}{l}\text { Driver's compartment and } \\
\text { microscope workstation }\end{array}$ \\
\hline $\begin{array}{l}\text { Helander and Lin } \\
\quad(2002)\end{array}$ & $\begin{array}{l}\text { From embodiment } \\
\text { design }\end{array}$ & Not explicit & - & Microscope workstation \\
\hline $\begin{array}{l}\text { Helander and Jiao } \\
\text { (2002) }\end{array}$ & $\begin{array}{l}\text { From embodiment } \\
\text { design }\end{array}$ & Not explicit & - & Usability testing \\
\hline Karwowski (2005) & $\begin{array}{l}\text { From embodiment } \\
\text { design }\end{array}$ & No & - & $\begin{array}{l}\text { Rear lighting (braking display) } \\
\text { system of an automobile }\end{array}$ \\
\hline Heo and Lee (2007) & $\begin{array}{l}\text { From embodiment } \\
\text { design }\end{array}$ & No & - & Nuclear power plants \\
\hline $\begin{array}{l}\text { Helander (2007) and Lo } \\
\text { and Helander (2007) }\end{array}$ & $\begin{array}{l}\text { From embodiment } \\
\text { design }\end{array}$ & No & - & $\begin{array}{l}\text { Dual reservoir system } \\
\text { simulation }\end{array}$ \\
\hline $\begin{array}{l}\text { Ghemraoui, Mathieu, } \\
\text { and Tricot (2009a) }\end{array}$ & $\begin{array}{l}\text { From conceptual } \\
\text { design }\end{array}$ & Not explicit & Systematic approach & $\begin{array}{l}\text { Agricultural machinery: } \\
\text { three-point hitch }\end{array}$ \\
\hline $\begin{array}{l}\text { Sadeghi (2014) and } \\
\text { Sadeghi et al. } \\
\text { (2013a, 2013b, 2015) }\end{array}$ & $\begin{array}{l}\text { From conceptual } \\
\text { design }\end{array}$ & Not explicit & $\begin{array}{l}\text { Systematic approach, } \\
\text { FTA, TRIZ }\end{array}$ & $\begin{array}{l}\text { Agricultural machinery: tractor } \\
\text { Power take-off driveshaft } \\
\text { and three-point hitch }\end{array}$ \\
\hline
\end{tabular}

Sadeghi et al. attempted to operationalise the IRAD method (Sadeghi 2014; Sadeghi et al. 2013a, 2013b, 2015). To do this, they suggested a DfHS method using two sequential methods. The first method proposed a functional reverse engineering for safety (FRES) approach underpinned by $A D$ to obtain design feedback from knowledge of an existing system. The aim of FRES is to acquire the original intrinsic design and safety knowledge integrated in the functional models of existing systems. The second method proposed a functional RE-engineering for safety (FR2ES) approach using AD theory to define a system with good mechanical safety that is reliable and robust, and with few possible human errors. Sadeghi et al. (2015) defined a safety indicator for safety level assessment. This indicator can measure safety from the conceptual design phase because, according to AD, a good design is a design with no coupling between the FRs. This consideration is included in this safety indicator. Reliability, which involves the life of the system, cannot be assessed in the embodiment design phase. It is also taken into account in calculating this indicator but is considered optimal in the conceptual design phase.

The results of this literature review of AD in DfHS are presented in Table 4. In these research works, utilisation conditions are not taken into account explicitly during the design phase and there is always a gap between what is imagined in design and what is experienced during product utilisation.

\subsection{FBS in DfHS}

\subsubsection{Introduction to FBS}

FBS was first introduced by Gero (1990) and Gero and Kannengiesser (2004) to model design as a process and capture the nature of the concepts manipulated during it by using a knowledge representation diagram. It points out that a structure expresses the internal and external states of a physical element. This type of framework considers that function and structure must be linked through behaviour to depict the action executed to complete a function, and to indicate how the structure fulfils the function (Sun et al. 2013). FBS defines 


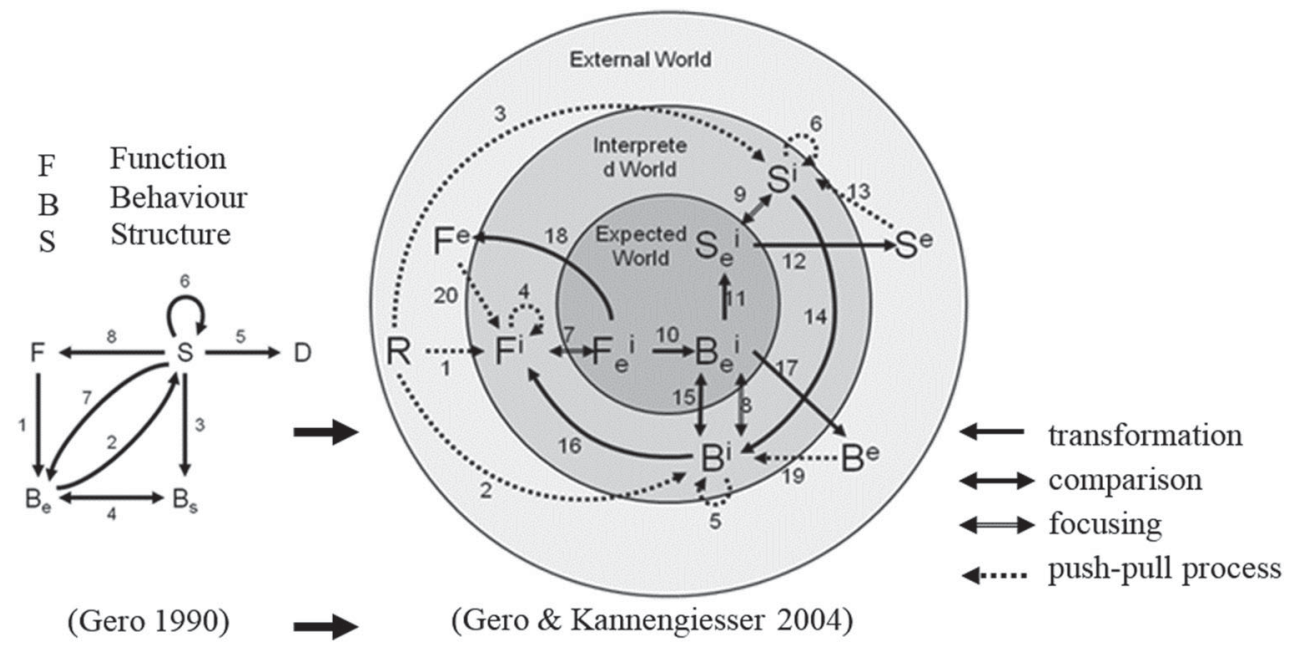

Figure 5. Gero's FBS framework.

function as being the intermediary between the human goal and the behaviour of a system. The FBS model focuses more on the design process, which is considered to be a transformation from intentions to structure. Early system design is considered as a process of function, behaviour and structure mapping. FBS ontology is not limited to the description of design objects. In 14 years, the FBS framework has evolved from a representation with 8 fundamental processes to a 20-step model (Figure 5) that includes the 8 original ones in a three-level perception of the world.

The starting point was originally the concept of function as the purpose of the system to be designed. Later, this changed to become the concept of requirement, an input given to the designer by the customer who indicates the design problem. The last step of the design process remains the same, the documentation (i.e. the description of the design, e.g. computer-aided design [CAD] drawings and component lists) used for construction or manufacture. The reader is referred to Gero (1990) and Gero and Kannengiesser (2004) for further details on FBS.

\subsubsection{Literature review of FBS in DfHS}

The application of FBS in human safety has been relatively rare. The authors of Houssin, Sun, and Gardoni (2010) and Sun et al. (2013) focused on integrating the utilisation conditions of mechanical products in the design process. In Houssin, Sun, and Gardoni (2010), they proposed a global view of the behavioural design approach (BDA) to help designers to analyse the interaction between user tasks and technical tasks, to evaluate system performance and find potential hazards. Then, in order to build a computer-aided system based on the BDA, they proposed a system framework for the BDA based on the hierarchical information model for engineering design (Sun et al. 2013). The unified modeling language (UML) was used to model the BDA system (Sun et al. 2013), by translating behavioural design modelling and their information models into computer language.

In these works, the behaviour concept of FBS was used to define system (structure) behaviour and user behaviour. Analysing the integration of these two behaviours allows 
Table 5. Literature review of FBS in DfHS.

\begin{tabular}{|c|c|c|c|c|}
\hline Reference & Design phase & $\begin{array}{l}\text { Work situation } \\
\text { analysis }\end{array}$ & $\begin{array}{l}\text { Integration with } \\
\text { other DTM and DTT } \\
\text { and techniques }\end{array}$ & Application \\
\hline $\begin{array}{l}\text { Houssin et al. } \\
\text { (2010) and Sun } \\
\text { et al. (2013) }\end{array}$ & $\begin{array}{l}\text { Behaviour analysis } \\
\text { in detailed } \\
\text { design }\end{array}$ & Yes & $\begin{array}{l}\text { Functional analysis, } \\
\quad A D\end{array}$ & $\begin{array}{l}\text { Socio-technical task related } \\
\text { to the rehabilitation of } \\
\text { disabled persons at work }\end{array}$ \\
\hline
\end{tabular}

determining the global behaviour in a work situation. However, this analysis is more useful for making comparisons than for creating designs. It should be noted that here, user behaviour concerns the user's task and does not include the service done by them. To overcome the shortcomings of these works, FBS can be integrated with product-service systems (PSS). FBS modelling covers the aspect of behaviour and models this allocation of functions. Regarding the PSS paradigm, they made a distinction between two kinds of behaviours: service behaviours and product behaviours. In other words, the interaction between PSS and FBS allows considering product behaviours and their interaction with service behaviours. The analysis of interaction between PSS and FBS allows considering any user activity performed in a work situation. The aim is to design human behaviours and products in parallel, not by designing only products or designing only human activities. This allows identifying and analysing the work situation from the conceptual design phase.

As it shown in Table 5, the application of FBS in DfHS has been relatively rare.

\subsection{Usability design and Kansei methodology in DfHS}

In this section, usability design and Kansei methodology that consider human factors in design are presented.

Usability is an important consideration in design, because it is concerned with the extent to which the users (persons who interact with the product) are able to work effectively, efficiently and with satisfaction. This concept is defined as 'the extent to which a product can be used by specified users to achieve specified goals with effectiveness, efficiency and satisfaction in a specified context of use' (NF EN ISO 9241-11 1998). Indeed, usability can be considered as the contribution made by human factors to product design. We introduce this concept before presenting a review on usability in DfHS.

Gould and Lewis (1985) believed that to achieve usability three conditions must be provided: a description of the users; the measurement of interest; and the tasks to be performed, and the circumstances in which they must be performed. So, three principles of system design must be complied with in usability design:

- Early focus on users (user-centricity): Designers should think about human factors in the design process. In other words, the designer must study the user's cognitive, behavioural, anthropometric and attitudinal characteristics, and also the nature of the work expected to be accomplished (Gould and Lewis 1985). The concept of user-centred design (UCD) is applied to human-computer interaction design. An overview of 12 key principles for involving end users in human-computer interaction development processes was developed by Gulliksen et al. (2003). They defined UCD in terms of a process 
where work usability and user involvement are closely integrated in the development process.

- Empirical measurement: In product design, the intended users should use simulations and prototypes to carry out real work, and their performance and reactions should be observed, recorded and analysed (Gould and Lewis 1985). To perform their empirical measurements, Gould and Lewis considered two factors: the need for actual behavioural measurements of learnability and usability, and the need for conducting these experimental and empirical studies very early in the development process.

- Iterative design: the goals to be reached are to make a system easy to use, user friendly, easy to operate, simple, responsive and flexible. Reaching these goals requires a process and that design must be iterative. In other words, there must be a cycle of design, test and measure, and redesign, repeated as often as necessary (Gould and Lewis 1985).

Kansei methodology is another approach that considers human factors in the design process. Kansei is a Japanese word which means a consumer's psychological feeling and image regarding a new product. Kansei methodology systematically explores users' perceptions of a product and translates these perceptions into DPs based on ergonomics and computer science (Nagamachi 1995). Nagamachi listed four points concerning this methodology: (1) how to grasp the consumer's feeling about the product in terms of ergonomic and psychological estimation; (2) how to identify the design characteristics of the product from the consumer's Kansei; (3) how to build Kansei Engineering as an ergonomic technology and (4) how to adjust product design to the current societal change or people's preference trend.

These approaches do not focus on human safety, but they do consider human factors during design. Usability is considered as the contribution of human factors to product design; therefore, it is an important consideration in the DfHS. In other words, an unsafe product will not be effective, efficient, or satisfying to users. Certain hazards and related accidents concern how products are used rather than mechanical defects. Designers should look beyond how to deal with potential hazards in order to consider safety in the context of usability (Li et al. 2001). They should control the environment of usage and the ways people use a product. The consideration of human factors can help designers to prevent potential hazards during design and ensure that their product is reasonably safe for its intended users.

Some works have dealt with ergonomic design in DfHS. For example, in the framework of the research conducted by the INRS, ${ }^{1}$ Fadier, Poyet, and Neboit (1991) proposed a method called MAFERGO to contribute ergonomic analyses of real work situations. This method combines technical analyses of reliability with ergonomic analyses of the activity, to better understand the different work situations and to compare them with the technical solutions proposed during design. Other authors Sagot, Gouin, and Gomes (2003) have described the contribution of ergonomists in the design of new products. They believe that the ergonomist ensures that the specificity of the human factor is incorporated in the design approach. Their analyses allow: (1) advising the designer on who the user is in order to design products adapted to his or her ways of working, expectations and needs and (2) help the designer assess the consequences of the design choices made in terms of safety, health, comfort and efficiency. However, these works are not in the scope of our study. 
This literature review indicates that the most of the DTM can intervene quite late in the design process, often only in the detailed design phase, when significant decisions about product principles and structures have been taken. It also shows that in most research, analysis of the work situation analysis is either not considered or its consideration is not explicit.

\section{DTT for human safety}

Generally, DTT are used to support, improve or enable design processes. Certain tools or systems underlie design processes in general (e.g. CAD systems), while other tools specialise in facilitating selected parts of the process (Lutters et al. 2014). For decades designers have constantly developed tools and techniques to aid them in their work, e.g. QFD, various digital engineering tools, CAD, risk analysis techniques, etc., and their utilisation has become an important issue for enhancing the performance of product development. Some researchers use DTT to integrate safety in design. This section discusses DTT used by researchers to improve safety.

Previous analysis demonstrated that the subject of DTT for human safety has been covered by a wide range of studies. Research topics are broad and diversified. As a result, six main groups of construction safety research emerged. The first group involves the utilisation of FA in integrating safety in the design process. The second group uses QFD in DfHS. The third one mainly focuses on how CAD could be used in improving safety during design. The fourth group pays attention to using risk analysis techniques in DfHS. The fifth group focuses on task and activity analysis in DfHS. The last one provides human safety in design through workstation design.

\subsection{FA in DfHS}

\subsubsection{Introduction to FA}

FA provides the functional description of a system. FA is defined in NF EN 1325 (2014) as a 'process that fully describes the functions and their relationships, which are systematically characterised, classified and evaluated'. It covers two approaches:

- The functional needs analysis (or external function analysis) which describes the needs that the product will satisfy in the form of user-related functions and constraints.

- The technical function analysis (or internal function analysis) which contributes to studying and formalising the product architecture by identifying the product-related functions.

One example of an FA tool is the function analysis systems technique (Wixson 1999) which focuses on the functions required by a design, process or service to accomplish its objective.

\subsubsection{Literature review of FA in DfHS}

Jouffroy et al. (1999) proposed a distributed design model to integrate safety principles in design. Their approach combines an ergonomic approach with an FA, and which places the emphasis on hazard identification and analysis in man/machine systems. 
Table 6. Literature review of FA in DfHS.

\begin{tabular}{|c|c|c|c|c|}
\hline Reference & Design phase & $\begin{array}{l}\text { Work situation } \\
\text { analysis }\end{array}$ & $\begin{array}{l}\text { Integration with other DTM } \\
\text { and DTT and techniques }\end{array}$ & Application \\
\hline $\begin{array}{l}\text { Jouffroy et al. } \\
\text { (1999) }\end{array}$ & $\begin{array}{l}\text { From conceptual } \\
\text { design }\end{array}$ & No & Ergonomic approach & $\begin{array}{l}\text { Numerically controlled } \\
\text { woodworking machines }\end{array}$ \\
\hline $\begin{array}{l}\text { Marsot and } \\
\quad \text { Claudon (2004) }\end{array}$ & $\begin{array}{l}\text { From conceptual } \\
\text { design }\end{array}$ & No & QFD and TRIZ & Boning knife \\
\hline
\end{tabular}

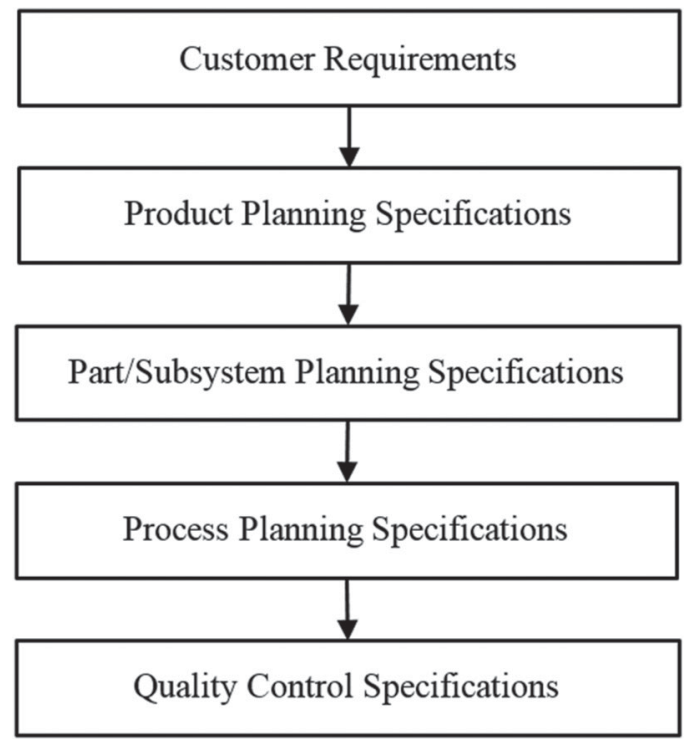

Figure 6. QFD approach (Franceschini 2002).

As explained in Section 3, Marsot and Claudon (2004) proposed an approach based on TRIZ, FA and QFD to integrate ergonomics in design. They believe that FA allows ergonomists to take part in drafting specifications for the product to be designed and to formalise ergonomics-related expectations.

Table 6 shows the results of this literature review of FA in DfHS. The FA techniques normally do not consider the activities of the future users or the potential contexts of use.

\subsection{QFD in DfHS}

\subsubsection{Introduction to QFD}

QFD is a method for introducing quality in design to satisfy the customer and to transform customer requirements into design objectives and key points that will be required to ensure quality during production. The QFD process (Figure 6) begins by pinpointing customer requirements, which are usually expressed in terms of qualitative characteristics.

During the product development process, customer requirements are successively converted into design specifications (Franceschini 2002). Indeed, this technique translates customer requirements, which are usually obtained from market surveys or customer interviews, into the technical characteristics of a product or service. The designer should determine the relationship between customer requirements and engineering characteristics, 


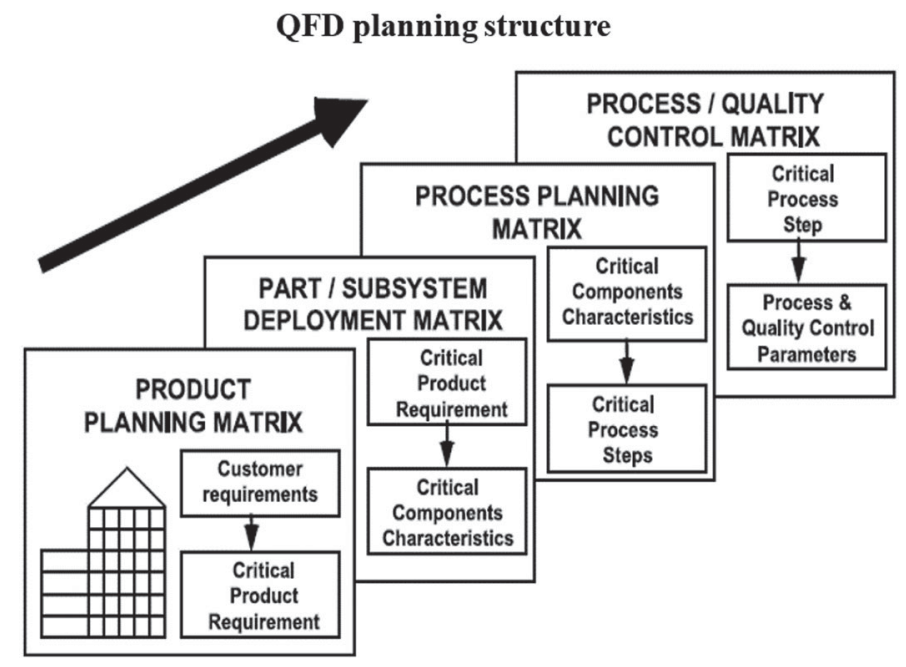

Figure 7. The logical sequence of QFD forms (Franceschini 2002).

the correlation between customer requirements, and the correlation between engineering characteristics (Liu and Tsai 2012).

Quality tables are used to represent the variables that concur to define a given project. They show the various relationships existing between them, supplying useful indications of the levels at which they interact and of the way they interact. Normally, four forms are used, each one enabling the user to focus, with varying degrees of detail, on the key aspects and on the interactions occurring between the various functions. Figure 7 illustrates the structure as well as the logical sequence of these forms. The first two forms (house of quality and part characteristics) refer to product planning; the second two (process planning matrix and process and quality control matrix) refer to manufacturing process planning and quality control (Franceschini 2002). The most often used and best known matrix is called house of quality (HoQ). In addition to 'What/How' correlations, this matrix involves a paired comparison of the different 'Hows' (Madu 2000).

\subsubsection{Literature review of QFD in DfHS}

Some papers have illustrated the applicability of QFD in DfHS. However, they are relatively rare. The following is a brief description of these papers.

As mentioned in Section 3.1, Marsot and Claudon (2004) proposed an approach based on TRIZ, i.e. FA and QFD, to integrate ergonomics in design. They proposed using QFD in two steps for linking ergonomics-related needs to the definition of product DPs: the first step in establishing HoQ involves listing customer needs (a Whats list), and the second step involves listing DPs (a Hows list) that will enable the previously identified needs to be satisfied.

Marsot adds to the QFD safety goals extracted from experience feedback (Marsot 2005). He starts with a list of safety and technical requirements and demonstrates their correlation with technical solutions by using the QFD matrix. The definition of ergonomic requirements is derived from the analysis of user activity. This approach consists in analysing the detailed design compared to the initial objectives. 
Table 7. Literature review of QFD in DfHS.

\begin{tabular}{lcccc}
\hline Reference & Design phase & $\begin{array}{c}\text { Work situation } \\
\text { analysis }\end{array}$ & $\begin{array}{c}\text { Integration with other DTM } \\
\text { and DTT and techniques }\end{array}$ & Application \\
\hline $\begin{array}{l}\text { Marsot and } \\
\text { Claudon (2004) }\end{array}$ & $\begin{array}{c}\text { From conceptual } \\
\text { design } \\
\text { Marsot (2005) }\end{array}$ & No & $\begin{array}{c}\text { Functional analysis and } \\
\text { TRIZ }\end{array}$ & Hand tool: boning kknife \\
Liu and Tsai (2012) & $\begin{array}{c}\text { Detailed design } \\
\text { Bas (2014) }\end{array}$ & No & $\begin{array}{c}\text { Analytic network process } \\
\text { (ANP), FMEA }\end{array}$ & A telecom engineering company \\
\hline
\end{tabular}

Other authors (Liu and Tsai 2012) integrated three approaches, namely QFD, fuzzy analytic network process (ANP), fuzzy failure modes and effect analysis (FMEA) in order to develop a systematic risk assessment framework. They proposed a fuzzy risk assessment method to provide a prevention and improvement technique to counter occupational hazards. Their method used two-stage QFD tables to represent the relationships among construction items, hazard types and hazard causes. A fuzzy ANP method was developed to identify important hazard types and hazard causes. FMEA was performed to assess the risk value of hazard causes based on the fuzzy inference approach. Their proposition can provide satisfactory risk assessment values of hazard causes and relevant improvement strategies.

In Bas (2014), an integrated methodology for QFD, scheduling and capital budgeting for preventive/protective measures was proposed. Bas (2014) proposed three HoQs to consider the interrelationships between tasks and hazards, hazards and events, and events and preventive/protective measures. In HoQ1, the list of tasks, the hazards that may arise from performing these tasks, and the relationship scores between the tasks and hazards, are determined. In HoQ2, the events that may result from the available hazards and relationship scores between the hazards and events are defined. In HoQ3, the preventive/protective measures are prepared based on the events.

As illustrated in Table 7, the research on the applicability of QFD in DfHS did not consider work situation analysis during design.

\subsection{CAD in DfHS}

Some researchers have illustrated the applicability of CAD in DfHS. The following brief description of these research works is presented.

Hasan et al. (2003) proposed a model of a work situation to help the designer take safety requirements into account at the design stage. This model allows structuring the necessary information to integrate safety aspects in a product model. Its aim is to capitalise and reuse this knowledge. It uses a meta-modelling principle to represent and group all the information related to the system and its environment in one database. A softwareaided design approach was proposed by Houssin et al. (2006) to facilitate communication between the various actors of all trades, the capitalisation of knowledge and use design history. This software allows using the information relative to the behaviour of the production system during use, and integrating all the types of data at the right time in the design process. Houssin and Cardoni (2009) proposed a model work situation using UML. This 
model is implemented by prototype software, namely computer-aided safety integration in design. This software helps designers to integrate safety in design. They did not propose to integrate this software in an existing CAD system.

Shahrokhi (2006) defined human models for their inclusion in the work situation during the design phases of industrial systems. To do this, he proposed an approach to identify the hazardous areas of work situations in a virtual environment or enhanced reality system. The main criticism of this work is the same as that regarding the work of Hasan. Namely, his proposal does not include design methods widely known and used by designers. In order to facilitate the analysis of barriers to implementation in complex systems, Shahrokhi proposes a virtual reality tool. This is also based on the concept of the work situation. The goal of his work was to define human models for their inclusion in work situations during the design phases of industrial systems. Shahrokhi and Bernard (2009) proposed a multiagent/multi-scale human modelling approach to facilitate the modelling and analysis of human performance in computerised 3D platforms. They explained the requirements for evaluating human performance during the design process. A performance analysis agent was proposed in response to these requirements and is used in a multi-agent/multi-scale architecture.

Määttä (2007) evaluated the impact of virtual environments on safety analysis and participatory ergonomics. His aim was to establish how virtual environments impact on the analysis process and how visualisation by computer modelling can be used effectively when applying participatory ergonomics.

Marsot, Ciccotelli, and Marc (2007) discussed the contribution of a dynamic risk-indexing tool applied in conjunction with virtual reality techniques. The aim of using virtual reality techniques was to imagine future operating situations and assess a priori associated risk levels. They illustrated how risk indexing enables the designer to better assess the relevance of their choices and thus to act retrospectively on their design. They also demonstrated how simulations using virtual reality techniques help to narrow the area of uncertainty between the viewpoint of the 'designer' and that of the end-user (Marc, Belkacem, and Marsot 2007).

Other authors (Coulibaly, Houssin, and Mutel 2008) presented an approach for maintainability and safety assessment in the design process using a CAD model enriched with behavioural semantic data. This CAD-based approach relies on a 3D model of the machine and a matrix that gathers information on component criticality, predicts safety, and assesses risk at an early design phase. The approach is aimed at assisting designers to take into account semantic behaviours using physical tests and/or other virtual reality systems.

Table 8 presents the results of this literature review of CAD in DfHS. As illustrated in this table, the work situation analysis is not explicit in these research works.

\subsection{Risk analysis techniques in DfHS}

\subsubsection{Introduction to risk analysis techniques}

Some researchers have tried to identify every possible technical hazard scenario and the corresponding potential consequences by using traditional hazard analysis tools. Safety analysis has often been seen as the identification and evaluation of risks (Harms-Ringdahl 1987). Harms-Ringdahl believes that safety analysis in design can be an efficient tool in 
Table 8. Literature review of CAD in DfHS.

\begin{tabular}{|c|c|c|c|c|}
\hline Reference & Design phase & $\begin{array}{l}\text { Work situation } \\
\text { analysis }\end{array}$ & $\begin{array}{l}\text { Integration with } \\
\text { other DTM and DTT } \\
\text { and techniques }\end{array}$ & Application \\
\hline Hasan et al. (2003) & From conceptual design & Not explicit & - & Printing line \\
\hline Shahrokhi (2006) & Detailed design & Not explicit & ETA & Band saw blade \\
\hline Houssin et al. (2006) & From conceptual design & Not explicit & - & Printing line \\
\hline Määttä (2007) & Detailed design & Not explicit & $\begin{array}{l}\text { Participatory } \\
\text { Ergonomics }\end{array}$ & $\begin{array}{l}\text { Machinery systems of } \\
\text { six workshops in a } \\
\text { steel factory }\end{array}$ \\
\hline $\begin{array}{l}\text { Marsot, Ciccotelli, and } \\
\text { Marc (2007) }\end{array}$ & From conceptual design & No & Risk-indexing tool & Industrial machinery \\
\hline $\begin{array}{l}\text { Coulibaly, Houssin, and } \\
\text { Mutel (2008) }\end{array}$ & Detailed design & Not explicit & - & $\begin{array}{l}\text { Movement transfer } \\
\text { system }\end{array}$ \\
\hline $\begin{array}{l}\text { Houssin and Cardoni } \\
\text { (2009) }\end{array}$ & Detailed design & Not explicit & - & Auto web-up \\
\hline $\begin{array}{l}\text { Shahrokhi and Bernard } \\
\text { (2009) }\end{array}$ & Detailed design & Not explicit & - & Operational platform \\
\hline
\end{tabular}

decreasing accident risks. Various risk analysis techniques exist. According to Liu and Tsai (2012), risk analysis techniques can be divided into three major categories:

- Qualitative analysis (e.g. preliminary hazard analysis [PHA], hazard and operability [HAZOP]) is the most widely used approach due to its simple execution process;

- Semi-quantitative analysis (e.g. FMEA) is also widely utilised; its principle is to analyse the level of hazards and risks according to former experiences and judgments;

- Quantitative analysis (e.g. fault tree analysis [FTA], event tree analysis [ETA]) is used to accurately calculate risks.

These techniques are described briefly in the following.

PHA may be very useful for problem definition and risk identification. This approach can be described as an inductive and qualitative technique, and is presented in tabulated form (Ericson 2005).

The HAZOP approach is generally considered to be 'process industry' oriented and is mostly used in the chemical, pharmaceutical and food industries. It uses simple guided words such as No/Not/None, More, Less, Reverse to enable the analyst to find deviations from normality. It is inductive and qualitative, and is presented in tabulated form (Ericson 2005).

FMEA includes the assessment of the effects of each potential failure mode of the components of a system on the latter's various functions, and the identification of potential failure modes impacting on its availability, reliability, maintainability and safety. FMEA is an inductive and qualitative approach, presented in tabulated form and accompanied with recommendations (Ericson 2005).

The FTA technique has been frequently used for accident analysis, as it identifies the interrelationships between causes and their logic. This approach is used for the qualitative analysis of causes and for quantitative probabilistic assessments. Its format is a logic diagram with a 'top-down' tree structure. The FTA is a deductive approach (Ericson 2005).

Like FTA, ETA also has a tree structure. The basic principle applied in this method is to allow the study of potential accident sequences and the quantitative (probabilistic) assessment of each possible sequence; it works in the opposite way to FTA. The analysis starts by 
considering an initiating event and then, with other events related to the elementary systems, by constructing trees (Ericson 2005). The approach is generally inductive and used for the quantitative analysis of consequences and quantitative (probabilistic) risk assessments.

\subsubsection{Literature review of risk analysis techniques in DfHS}

Some papers have illustrated the applicability of risk analysis techniques in DfHS. A brief description of these papers is presented in the following.

Harms-Ringdahl (1987) believes that the success of safety integration during design depends on the care given to the risk analysis in the design process. To achieve this, he proposed an analysis process with seven steps to ensure safety during the design process: (1) safety policy (goals and purpose, extent and limits, resources), (2) obtain information required for hazard analysis, (3) identify hazards using one or more safety analysis methods, (4) evaluate the hazards identified, (5) identify potential risk control measures, (6) decide to select measures and (7) implementation. This procedure proposes to use existing safety analysis methods, but it does not specify which of these should be used to identify hazards or to evaluate risks.

Schoone-Harmsen (1990) proposed a design method to support the designer when designing products that are safe(r) to use, but it can also be an aid for the ergonomist when analysing the use of a product. This method has four steps: (1) analysis of the problem (defining the product's use and possible hazardous situations); (2) identification of critical factors (identifying factors that are critical in causing accidents); (3) synthesis, finding the solution (developing risk control measures that act on critical factors) and (4) evaluation of the effectiveness of the solutions. This method showed once again that a systematic step-by-step analysis and control procedure is essential to the integration of safety during design.

Stoop (1990) pointed out that safety becomes explicit in the design process at three decision points: (1) the selection of relevant use-scenarios, based upon the severity, nature and extent of the hazards involved; (2) the selection of a technological principle and energy source for further development and (3) the third decision is that of which hazards must be dealt with and thus which hazard patterns.

Gauthier and Charron (2002) proposed a systematic risk analysis and control procedure during machinery design. The proposed procedure encompasses six basic steps: (1) determination of the limits of machinery; (2) hazard identification; (3) estimation of the severity of the potential consequences of the hazards identified; (4) identification of the direct causes of the hazards; (5) estimation of the risk level associated with the hazards identified; (6) identification of the causes of the direct causes; (7) identification of the possibilities of controlling the hazards identified; (8) evaluation and selection of control measures and (9) development and implementation of selected hazard control measures.

Village, Greig, and Neumann (2011) developed an approach based on FMEA tools to address, concurrently and for the same failure, its consequences on product quality and on operator safety: 'human factors - failure mode and effects analysis' advantageously proposes specific rating tables for failure seriousness, occurrence or detection based on injury risk for production line workers. However, the starting point of this analysis is always a quality failure; certain potentially hazardous work situations, which would generate no quality risk, could be exempted from the analysis. 
Table 9. Literature review of Risk Analysis Techniques in DfHS.

\begin{tabular}{|c|c|c|c|c|}
\hline Reference & Design phase & $\begin{array}{l}\text { Work situation } \\
\text { analysis }\end{array}$ & $\begin{array}{l}\text { Risk analysis } \\
\text { techniques }\end{array}$ & Application \\
\hline Harms-Ringdahl (1987) & Detailed design & No & Not specific & Rolling machine \\
\hline $\begin{array}{l}\text { Schoone-Harmsen } \\
\text { (1990) }\end{array}$ & Detailed design & No & Not specific & - \\
\hline Stoop (1990) & Detailed design & No & Not specific & - \\
\hline $\begin{array}{l}\text { Gauthier and Charron } \\
\text { (2002) }\end{array}$ & Detailed design & Not explicit & FTA & $\begin{array}{l}\text { Agricultural machinery: wood } \\
\text { chipper }\end{array}$ \\
\hline $\begin{array}{l}\text { Shahrokhi and Bernard } \\
\text { (2010) }\end{array}$ & Detailed design & No & ETA, FTA & Numerical simulation process \\
\hline Village et al. (2011) & Detailed design & & FMEA & Assembly line design \\
\hline Sadeghi (2014) & $\begin{array}{c}\text { From conceptual } \\
\text { design phase }\end{array}$ & Not explicit & FTA & $\begin{array}{l}\text { Agricultural machinery: tractor } \\
\text { power take-off drive shaft and } \\
\text { three-point hitch }\end{array}$ \\
\hline Lux et al. (2015) & Detailed design & Not explicit & FMEA & $\begin{array}{l}\text { Assembly operation for a clip used to } \\
\text { secure an electrical wiring harness } \\
\text { on a plastic component }\end{array}$ \\
\hline
\end{tabular}

Lux et al. (2015) also proposed an FMEA model based on formalism called 'Work situation FMEA'. It prompts designer discussion around data relevant to real work situations and encourages discussion and decision-making around real work situations, by focusing special attention on health and safety issues affecting future operators (Lux et al. 2015).

Shahrokhi and Bernard (2010) developed a mathematical model based on the hypothesis used in ETA, FTA and energy flow/barrier analysis for modelling accidents.

Sadeghi (2014) used FTA for accident report analysis. The aim was to identify all the potential causes of a given accident. Based on accident causes, she proposed the safety objectives to mitigate risk during design.

Table 9 shows the results of the literature review of risk analysis techniques in DfHS. As illustrated in this table, most of the risk analysis techniques can be applied at the end of the design process (detailed design).

\subsection{Task and activity analysis in DfHS}

Another concept to be considered in DfHS is task analysis. Task analysis is one of the basic tools used by ergonomists in design (Drury 1983) found in the literature on human factors. Kirwan and Ainsworth defined task analysis as the study of what a user is required to do, in terms of actions and/or cognitive processes, to achieve a task objective (1992). Task analysis includes techniques for data collection, systems design, specification and evaluation, as well as analysis (Benyon 1992), which provide a description of the actions involved in carrying out a process (Lyons 2009).

This review shows that task analysis - except research such as that of Stoop (1990) - does not usually focus on human safety; it is for use in predictive human reliability analysis.

\subsection{Workstation design in DfHS}

The literature review showed that certain research on workstation design considers anthropometric and ergonomic aspects. Dukic, Rönnäng, and Christmansson (2007) believe that 
ergonomics is concerned with 'designing products according to human needs in order to optimise their well-being and overall system performance'. Indeed, ergonomics must be considered to ensure that the products designed satisfy customer requirements from the standpoints of ease of use and safety. Ergonomic characteristics can include body dimensions, posture, body movements, physical strength and mental abilities.

Human motion analysis and modelling for workstation design have been dealt with by many researchers. A structural methodology for ergonomic workstation design based on virtual manufacturing and response surface methodology was developed by Ben-Gal and Bukchin (2002). Mavrikios et al. developed a motion analysis and prediction method by using a statistical analysis of experiments approach (2006). In Jung, Kwon, and You (2009), digital human models were employed to design and visualise workstations. Recently, Mahoney, Kurczewski, and Froede (2015) developed a design method for multi-user workstations utilising anthropometry and preference data. Savin, Gaudez, and Marsot (2015) developed a dynamic digital human model based on robotics and physics simulation, controlled automatically in force and acceleration and inspired by human motor control.

This review shows that workstation design does not usually focus specifically on human safety. Indeed, anthropometric and ergonomic aspects are considered in workstation design to analyse and model human motion.

Overall, the findings of the surveys and the literature reviewed indicate that most of the DTT can intervene quite late in the design process, often only in the detailed design phase, when significant decisions on the product's principles and structures have been taken.

\section{Discussion}

\subsection{Chronological discussion}

As shown in Figure 8, the number of relevant papers published annually is not large, fewer than 10 before 2002. In general, an increasing number of relevant papers have been published gradually since 2002. It is noted that there were six relevant papers in 2007, and the overall trend of DfHS is upward.

\subsection{Thematic discussion}

This paper summarises our findings based on our literature review of research on DfHS. Our overall goal here is to investigate research works which apply DMT and DTT to improve safety by focusing specifically on the identification and analysis of work situations. Figure 9 synthesises research on DfHS.

\subsection{Research findings}

It is important to note the need to summarise the major highlights of two previous sections before moving on to the recommendations and future works. The following are two main findings of this research.

Overall, the findings of the surveys and literature reviewed indicate that most of the publications on these subject offered solutions that can intervene quite late in the design process, essentially in the detailed design phase, when significant decisions on product 
principles and structures have been taken. Most of the methods used early in the design process generally present constraints and are used for verification and validation. Among the research works reviewed that of Ghemraoui and her colleagues, Ghemraoui, Mathieu, and Tricot (2009a, 2009b) and Sadeghi et al. (2013a, 2013b) should be highlighted. Their proposal consists of a general suggestion for systematic risk identification and humansafety integration in the early design phase. But their works do not explicitly take into account the conditions of utilisation during the design phase.

Another significant part of the literature provided contributions on DTM. AD and FBS theories appear to be more effective in the context of DfHS. AD theory is useful in this context because of its capacity to present design requirements and associated DPs, and includes criteria for evaluating designs. FBS theory emphasises the need to consider human performance in the design process, thus permitting work situation analysis.

\subsection{Research gaps and agenda}

There is a large corpus of academic studies already performed on DfHS, and which have demonstrated many benefits for the design process. Two main groups including a total of 44 types of safety design research topics have been identified in this review. Nevertheless, we have determined three research gaps which will be discussed below. We also propose a corresponding research agenda.

The literature shows that DfHS is a very complicated subject characterised by several factors including systemic, human and environmental ones. Consequently, designers tend to use tools and techniques that normally focus on the use of a product and not only its design. The literature reviews also showed that the conditions of utilisation are not or are hardly taken into account during the design phase, and that there is always a gap between what is imagined in the design and what is experienced when using the product. Indeed, one of the main sources of risk is linked to the variety of work situations. To take into account this variety, the aim in design is to take into account human behaviours demonstrated in

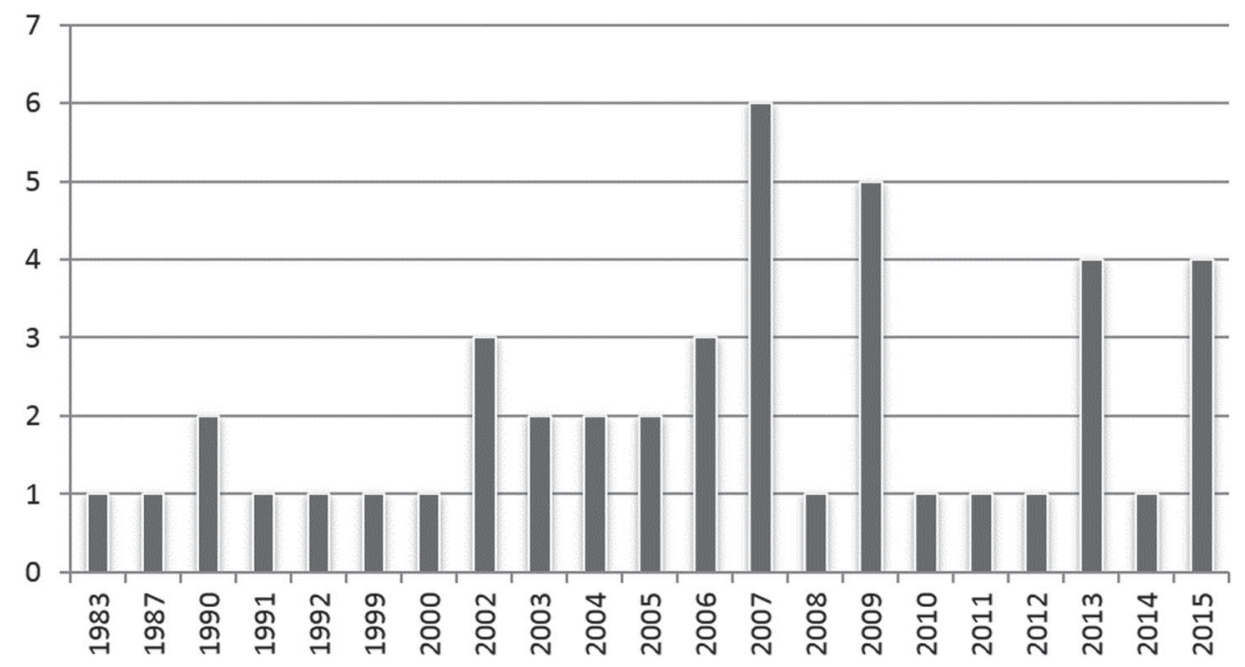

Figure 8. Year of publications (till December 2015). 


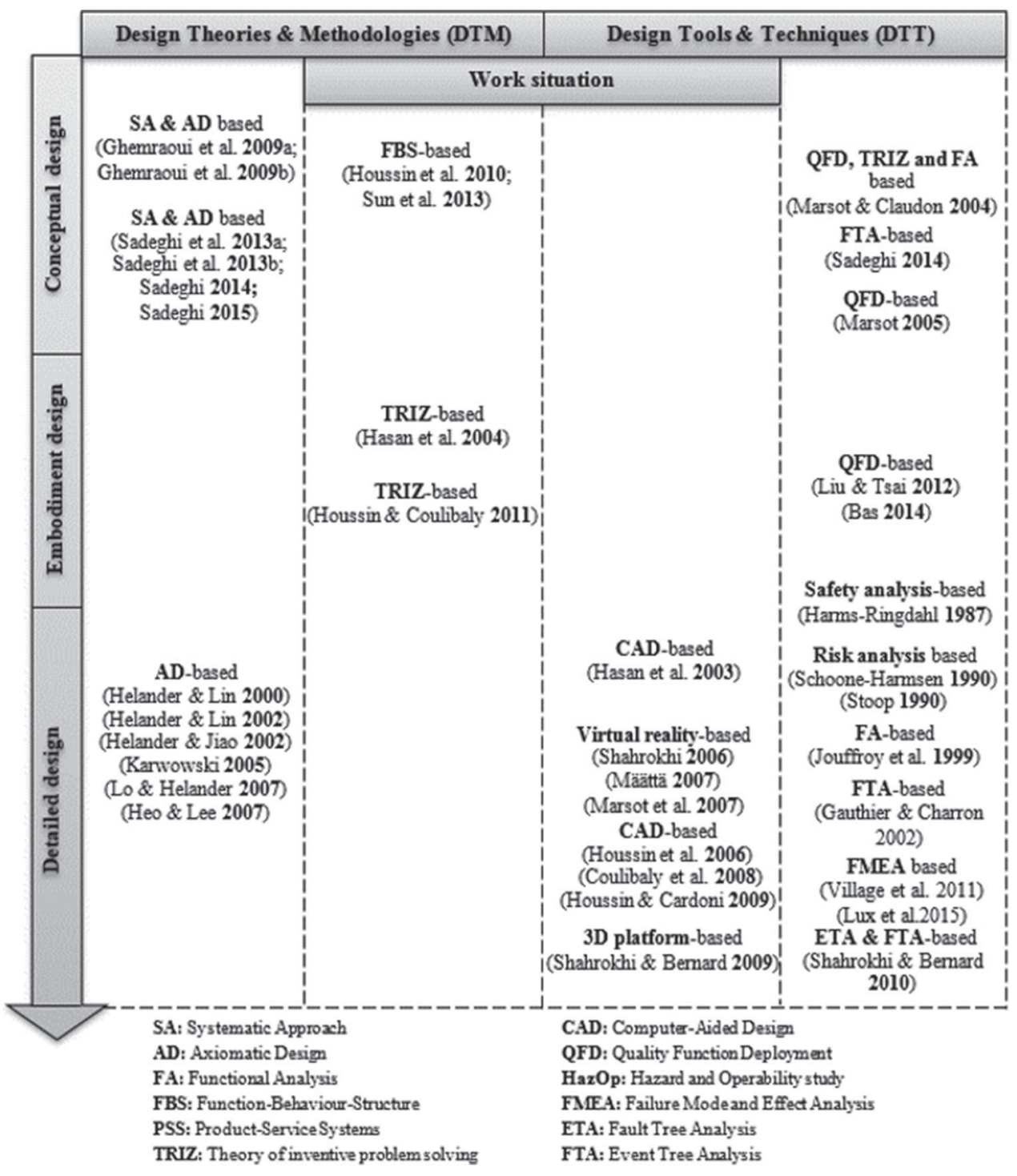

Figure 9. Research in DfHS.

work situations in parallel with the product, so as not to focus only on product design or only on designing human activities. To this end, the interaction between PSS and FBS, which allows considering product behaviours and their interaction with service activities, could be considered. This interaction and its analysis are helpful for work situation analysis.

The review of several previous designs for human safety research works illustrated that expert opinions or judgements are often used to assess the probability of occurrence of risk in the context of DfHS. For future research directions, one path could be to investigate a method capable of taking into account uncertainties associated with expert judgements.

The literature also revealed the need for continuous improvement in safety management. To assess how this can be effectively achieved, it is pertinent to note the vital role of 
knowledge on the nature and causes of accidents. Thus for future research, one direction could be to use knowledge engineering approaches to formalise knowhow in DfHS.

\section{Conclusion}

The number of peer-reviewed papers published and the range of research topics related to the improvement of safety during the design process has increased. However, the variety of topics and the number of papers makes it difficult for researchers and practitioners to have an overview of the field. Thus this comprehensive literature review evaluated 26 peerreviewed papers published in 10 journals with high reputations in the field of construction management and safety research. A seven-step systematic review was conducted in this research.

An overview and analysis of these studies were carried out based on (1) the author(s) name(s), (2) title of the paper, (3) the year of publication of each paper and (4) the title of the journal. This review identified 44 research topics that were clustered into two main research groups.

The first group focused on the application of DTM in DfHS in manufacturing systems, while the other focused on the use of DTT in DfHS in manufacturing systems. After discussing the research topics from the chronological and thematic perspectives, two main research findings were obtained. Most of publications on DfHS offered solutions that can intervene quite late in the design process. The works that propose solutions in the upstream phase of design do not explicitly take into account the conditions of utilisation during the design phase. Another significant part of the literature provided contributions on DTM. AD and FBS theories appear to be more effective in the context of DfHS. Finally, this systematic review identified and discussed two research gaps: expert opinions or judgements are often used to assess the probability of the occurrence of risk in the context of DfHS. The literature also revealed the need for continuous improvement in safety management. To answer these issues, a research agenda was proposed to provide directions for future research on DfHS.

\section{Note}

1. French National Research and Safety Institute (French: Institut national de recherche et de sécurité, INRS).

\section{Acknowledgements}

The authors would like to acknowledge the Paris Nouveaux Mondes programme of the heSam University for their financial support.

\section{Disclosure statement}

No potential conflict of interest was reported by the authors.

\section{References}

Alting, L., and J. Jøgensen. 1993. “The Life Cycle Concept as a Basis for Sustainable Industrial Production." CIRP Annals - Manufacturing Technology 42 (1): 163-167. 
Altshuller, G. 1984. Creativity as an Exact Science. New York, NY: Gordon and Breach Science Publishers. Altshuller, G. 1999. The Innovation Algorithm. Worcester, MA: Technical Innovation Center.

Andreasen, M. M. 2011. "45 Years with Design Methodology." Journal of Engineering Design 22 (May 2015): 293-332.

Bas, E. 2014. "An Integrated Quality Function Deployment and Capital Budgeting Methodology for Occupational Safety and Health as a Systems Thinking Approach: The Case of the Construction Industry." Accident Analysis and Prevention 68: 42-56. doi:10.1016/j.aap.2013.10.005.

Ben-Gal, I., and J. Bukchin. 2002. "The Ergonomic Design of Workstations Using Virtual Manufacturing and Response Surface Methodology." IIE Transactions 34: 375-391.

Benyon, D. 1992. "The Role of Task Analysis in Systems Design." Interacting with Computers 4: 102-123.

Boothroyd, G., and P. Dewhurst. 1983. Design for Assembly: A Designer's Handbook. Technique Report, Department of Mechanical Engineering, University of Massachusetts.

Chinniah, Y. 2015. "Analysis and Prevention of Serious and Fatal Accidents Related to Moving Parts of Machinery." Safety Science 75: 163-173. http://linkinghub.elsevier.com/retrieve/pii/S09257535150 00326.

Chiu, M.-C., and G. E. Okudan. 2010. "Evolution of Design for X Tools Applicable to Design Stages: A Literature Review." Paper presented at the proceedings of the ASME 2010 international design engineering technical conferences \& computers and information in engineering conference information in engineering conference, 1-12.

Coulibaly, A., R. Houssin, and B. Mutel. 2008. "Maintainability and Safety Indicators at Design Stage for Mechanical Products." Computers in Industry 59 (5): 438-449. Accessed March 22, 2013. http://linkinghub.elsevier.com/retrieve/pii/S0166361507001856.

Dixon, J. R., and C. Poli. 1995. Engineering Design and Design for Manufacturing: A Structured Approach. Conway, MA: Field Stone.

Drury, C. G. 1983. "Task Analysis Methods in Industry." Applied Ergonomics 14 (1): 19-28.

Duijne, F. van, A. Hale, H. Kanis, and B. Green. 2007. “Design for Safety: Involving Users' Perspectives. Redesign Proposals for Gas Lamps Using a Pierceable Cartridge." Safety Science 45: 253-281.

Dukic, T., M. Rönnäng, and M. Christmansson. 2007. "Evaluation of Ergonomics in a Virtual Manufacturing Process." Journal of Engineering Design 18 (2): 125-137.

Ericson, I. 2005. Hazard Analysis Techniques for System Safety. Hob: Wiley.

European Commission. 1989. "Directive 89/392/EEC of the European Parliament and of the Council Directive of 14 June 1989 on the Approximation of the Laws of the Member States Relating to machinery (OJ L 183, 29 June)."

European Commission. 2006. "Directive 2006/42/EC of the European Parliament and of the Council 17 May 2006 on Machinery, and Amending Directive 95/16/EC (Recast). OJ. 2006; L157:24-86."

European Committee for Standardization (CEN). 2010. "Safety of Machinery - General Principles for Design - Risk Assessment and Risk Reduction." Brussels: CENELEC; 2010. Standard No. NF EN ISO 12100:2010.

Fadier, E., and J. Ciccotelli. 1999. "How to Integrate Safety in Design: Methods and Models." Human Factors and Ergonomics In Manufacturing 9 (4): 367-379.

Fadier, E., C. Poyet, and M. Neboit. 1991. "Advantage of an Integrated Approach of Reliability and Ergonomical Ana-Lysis (Application to a Hybrid System of Sequential Production)." In Designing for Everyone, edited by Y. Quéinnec and F. Daniellou, 477-479. London: Taylor \& Francis.

Franceschini, F. 2002. Advanced Quality Function Deployment. Boca Raton, FL: CRC Press LLC. http://6sigmaindia.in/Documents/R4 Quality Function Deployment.pdf, http://scholar.google. $\mathrm{com} / \mathrm{scholar}$ ?hl = en\&btnG = Search\&q=intitle:advanced+quality+function+deployment\#0.

Gauthier, F., and F. Charron. 2002. "A Structured Procedure of Risk Analysis and Control for Safety Integration in Machinery Design." Journal of Engineering Design 13: 77-99.

Ge, P., S. C. Y. Lu, and N. P. Suh. 2002. "An Axiomatic Approach for 'Target Cascading' of Parametric Design of Engineering Systems." CIRP Annals - Manufacturing Technology 51 (1): 111-114.

Gero, J. S. 1990. "Design Prototypes: A Knowledge Representation Scheme for Design." Al Magazine 11 (4): 26-36.

Gero, J. S., and U. Kannengiesser. 2004. "The Situated Function-Behaviour-Structure Framework." Design Studies 25: 373-391. 
Ghemraoui, R., L. Mathieu, and N. Tricot. 2009a. "Design Method for Systematic Safety Integration." CIRP Annals - Manufacturing Technology 58: 161-164.

Ghemraoui, R., L. Mathieu, and N. Tricot. 2009b. "Systematic Human-Safety Analysis Approach Based on Axiomatic Design Principles." Paper presented at the proceedings of the 5th international conference on axiomatic design, ICAD 2009, 8. http://www.axiomaticdesign.com/technology/ icad/icad2009/icad2009_01.pdf.

Gould, J. D., and C. Lewis. 1985. "Designing for Usability: Key Principles and What Designers Think." Communications of the ACM 28 (3): 300-311.

Gulliksen, J., B. Göransson, I. Boivie, S. Blomkvist, J. Persson, and Å. Cajander. 2003. “Key Principles for User-Centred Systems Design." Behaviour \& Information Technology 22 (6): 397-409.

Hale, A., and D. Borys. 2013. "Working to Rule, or Working Safely? Part 1: A State of the Art Review." Safety Science 55: 207-221. doi:10.1016/j.ssci.2012.05.011.

Harms-Ringdahl, L. 1987. "Safety Analysis in Design-Evaluation of a Case Study." Accident Analysis and Prevention 19 (4): 305-317.

Hasan, R., A. Bernard, J. Ciccotelli, and P. Martin. 2003. "Integrating Safety into the Design Process: Elements and Concepts Relative to the Working Situation." Safety Science 41 (2-3): 155-179. http://linkinghub.elsevier.com/retrieve/pii/S0925753502000024.

Hasan, R., P. Martin, and A. Bernard. 2004. "Solving Contradictions Problems Related To Safety Integration In Design Process." Paper presented at the proceedings of the TRIZ conference, Nancy.

Helander, M. G. 2007. “Using Design Equations to Identify Sources of Complexity in Human-Machine Interaction." Theoretical Issues in Ergonomics Science 8 (2): 123-146.

Helander, M. G., and J. Jiao. 2002. "Coupling in Design of Human Computer Interaction." Paper presented at the proceedings of the second international conference on axiomatic design, ICAD 2002.

Helander, M. G., and L. Lin. 2000. "Anthropometric Design of Workstations." Paper presented at the proceedings of the first international conference on axiomatic design, ICAD 2000.

Helander, M. G., and L. Lin. 2002. "Axiomatc Design in Ergonomics and an Extension of the Information Axiom." Journal of Engineering Design 13 (4): 321-339.

van Hemel, C. G., and T. Keldman. 1996. "Applying 'Design for X' Experience in Design for Environment." In Design for X: Concurrent Engineering Imperatives, edited by G. Q. Huang, 72-95. London: Chapman \& Hall.

Heo, G., and S. K. Lee. 2007. "Design Evaluation of Emergency Core Cooling Systems Using Axiomatic Design." Nuclear Engineering and Design 237: 38-46.

Hollnagel, E. 2008. "Risk + Barriers = Safety?" Safety Science 46: 221-229.

Holt, R., and C. Barnes. 2010. "Towards an Integrated Approach to 'design for X': An Agenda for Decision-Based DFX Research." Research in Engineering Design 21: 123-136.

Houssin, R., A. Bernard, P. Martin, G. Ris, and F. Cherrier. 2006. "Information System Based on a Working Situation Model for a New Design Approach in Concurrent Engineering." Journal of Engineering Design 17 (1): 35-54. Accessed March 22, 2013. http://www.tandfonline.com/doi/abs/10.1080/095 44820500276048.

Houssin, R., and M. Cardoni. 2009. "Software Framework for the Approach: Computer Aided Safety Integration in Design Process (CASID)." Journal of Advanced Manufacturing Systems 8 (1): 27-45.

Houssin, R., and A. Coulibaly. 2011. "An Approach to Solve Contradiction Problems for the Safety Integration in Innovative Design Process." Computers in Industry 62 (4): 398-406. Accessed March 22, 2013. http://linkinghub.elsevier.com/retrieve/pii/S0166361510001818.

Houssin, R., H. Sun, and M. Gardoni. 2010. "A Behavioural Design Approach to Improving Mechanical System Design with Integration of Use Conditions." International Journal of Design and Innovation Research 5 (3): 1-24.

Huang, G. Q. 1996. Design for X: Concurrent Engineering Imperatives. London: Chapman \& Hall.

Jouffroy, D., S. Demor, J. Ciccotelli, and P. Martin. 1999. "An Approach to Integrate Safety at the Design Stage of Numerically Controlled Woodworking Machines." Integrated Design and Manufacturing in Mechanical Engineering. 2nd international conference on Integrated Design and 
Manufacturing in Mechanical Engi- Neering IDMME'98. Compiegne, France, May 27-29, 643-650, ISBN 0-7923-6024-9.

Jung, K., O. Kwon, and H. You. 2009. “Development of a Digital Human Model Generation Method for Ergonomic Design in Virtual Environment." International Journal of Industrial Ergonomics 39 (5): 744-748. doi:10.1016/j.ergon.2009.04.001.

Karwowski, W. 2005. "Ergonomics and Human Factors: The Paradigms for Science, Engineering, Design, Technology and Management of Human-Compatible Systems." Ergonomics 48 (5): 436-463.

Khan, F., S. Rathnayaka, and S. Ahmed. 2015. "Methods and Models in Process Safety and Risk Management: Past, Present and Future." Process Safety and Environmental Protection 98: 116-147. http://linkinghub.elsevier.com/retrieve/pii/S0957582015001275.

Kirwan, B., and L. K. Ainsworth. 1992. A Guide to Task Analysis. London: Taylor \& Francis.

Kjellén, U., and S. Sklet. 1995. "Integrating Analyses of the Risk of Occupational Accidents into the Design Process. Part I: A Review of Types of Acceptance Criteria and Risk Analysis Methods." Safety Science 18 (94): 215-227.

Kroll, E. 2013. "Design Theory and Conceptual Design: Contrasting Functional Decomposition and Morphology with Parameter Analysis." Research in Engineering Design 24: 165-183.

Kuo, T.-C., S. H. Huang, and H.-C. Zhang. 2001. "Design for Manufacture and Design for ' $X$ ': Concepts, Applications, and Perspectives." Computers \& Industrial Engineering 41:241-260. http://www. sciencedirect.com/science/article/B6V27-44B2119-1/2/06b78ac16a3e27ffddc83de87789d737.

Le Masson, P., K. Dorst, and E. Subrahmanian. 2013. "Design Theory: History, State of the Art and Advancements." Research in Engineering Design 24: 97-103.

Li, L., P. B. Chang, T. J. Ayres, C. T. Wood, and M. Park. 2001. "Usability Evaluation for Product Safety." Paper presented at the proceedings of the make it easy 2001, IBM's conference on Ease of Use, San Jose, CA, June 4-7, 1-7.

Liu, H.-T., and Y.-L. Tsai. 2012. "A Fuzzy Risk Assessment Approach for Occupational Hazards in the Construction Industry." Safety Science 50 (4): 1067-1078. doi:10.1016/j.ssci.2011. 11.021.

Lo, S., and M. G. Helander. 2007. "Use of Axiomatic Design Principles for Analysing the Complexity of Human-Machine Systems." Theoretical Issues in Ergonomics Science 8 (2): 147-169.

López-Arquillos, A., J. C. Rubio-Romero, and M. D. Martinez-Aires. 2015. "Prevention Through Design (PtD). The Importance of the Concept in Engineering and Architecture University Courses." Safety Science 73: 8-14.

Lutters, E., F. J. A. M. van Houten, A. Bernard, E. Mermoz, and C. S. L. Schutte. 2014. "Tools and Techniques for Product Design." CIRP Annals - Manufacturing Technology 63: 607-630. http://www.sciencedirect.com/science/article/pii/S0007850614001929.

Lux, A., J. M. De Bikond, A. Etienne, and E. Quillerou-grivot. 2015. "FMEA and Consideration of Real Work Situations for Safer Design of Production Systems." International Journal of Occupational Safety and Ergonomics (JOSE). doi:10.1080/10803548.2016.1180856.

Lyons, M. 2009. "Towards a Framework to Select Techniques for Error Prediction: Supporting Novice Users in the Healthcare Sector." Applied Ergonomics 40 (3): 379-395. doi:10.1016/j.apergo.2008. 11.004.

Määttä, T. 2007. "Human Motion Simulation for Vehicle and Workplace Design." Human Factors and Ergonomics in Manufacturing 17 (5): 435-443. http://scholar.google.com/scholar?hl = en\&btnG = Search\&q = intitle:Human+Motion+Simulation+for+Vehicle+and+Workplace+Design\#1.

Madu, C. N. 2000. House of Quality in a Minute. U. C. Fairfield, CT: Chi Publishers.

Mahoney, J. M., N. A. Kurczewski, and E. W. Froede. 2015. "Design Method for Multi-User Workstations Utilizing Anthropometry and Preference Data." Applied Ergonomics 46: 60-66. doi:10.1016/j.apergo.2014.07.003.

Marc, J., N. Belkacem, and J. Marsot. 2007. "Virtual Reality: A Design Tool for Enhanced Consideration of Usability 'Validation Elements'." Safety Science 45: 589-601.

Marsot, J. 2005. "QFD: A Methodological Tool for Integration of Ergonomics at the Design Stage." Applied Ergonomics 36: 185-192. 
Marsot, J., J. Ciccotelli, and J. Marc. 2007. "Dynamical Indexation of Risk in a Virtual Work Environment." International Journal of Product Development 4 (6): 570-586.

Marsot, J., and L. Claudon. 2004. "Design and Ergonomics. Methods for Integrating Ergonomics at Hand Tool Design Stage." International Journal of Occupational Safety and Ergonomics (JOSE) 10 (July 2015): 13-23.

Mavrikios, D., V. Karabatsou, K. Alexopoulos, M. Pappas, P. Gogos, and G. Chryssolouris.. 2006. "An Approach to Human Motion Analysis and Modelling." International Journal of Industrial Ergonomics 36: 979-989.

Nagamachi, M. 1995. “Kansei Engineering: A New Ergonomic Consumer-Oriented Technology for Product Development." International Journal of Industrial Ergonomics 15: 3-11.

Nepal, B., L. Monplaisir, and N. Singh. 2006. "A Methodology for Integrating Design for Quality in Modular Product Design." Journal of Engineering Design 17 (5): 387-409.

NF EN 1325. 2014. Value Management - Vocabulary - Terms and Definitions.

NF EN ISO 9241-11. 1998. Ergonomic Requirements for Office Work with Visual Display Terminals (VDTs) - Part 11: Guidance on Usability.

Pahl, G., W. Beitz, J. Feldhusen, and H. K. Grote. 2007. Engineering Design A Systematic Approach. London: Springer.

Rausand, M., and I. B. Utne. 2009. "Product Safety - Principles and Practices in a Life Cycle Perspective." Safety Science 47 (7): 939-947. doi:10.1016/j.ssci.2008.10.004.

Sadeghi, L. 2014. "Aide À La Décision Pour L'intégration de La Sécurité Au plus Tôt En Phase de Conception-Approche Innovante de Reconception de Machines Agricoles." École Normale Supérieure de Cachan.

Sadeghi, L., L. Mathieu, N. Tricot, and L. Al Bassit. 2015. "Developing a Safety Indicator to Measure the Safety Level during Design for Safety." Safety Science 80: 252-263. http://linkinghub.elsevier.com/ retrieve/pii/S092575351500209X.

Sadeghi, L., L. Mathieu, N. Tricot, L. Al Bassit, and R. Ghemraoui. 2013a. "Toward Design for Safety. Part 1: Functional Reverse Engineering Driven by Axiomatic Design." Paper presented at the proceedings of the 7th international conference on axiomatic design, ICAD 2013.

Sadeghi, L., L. Mathieu, N. Tricot, L. Al Bassit, and R. Ghemraoui. 2013b. "Toward Design for Safety. part 2: Functional Re-Engineering Using Axiomatic Design and FMEA." Paper presented the proceedings of the 7th international conference on axiomatic design, ICAD 2013.

Sagot, J.-C., V. Gouin, and S. Gomes. 2003. "Ergonomics in Product Design: Safety Factor." Safety Science 41: 137-154. http://linkinghub.elsevier.com/retrieve/pii/S0925753502000383.

Savin, J., C. Gaudez, and J. Marsot. 2015. "Dynamic Digital Human Models for Ergonomic Analysis Based on Humanoid Robotics Techniques." International Journal of the Digital Human 1 (1): 81-109.

Schoone-Harmsen, M. 1990. "A Design Method for Product Safety." Ergonomics 33 (4): 431-437.

Shahrokhi, M. 2006. "Intégration D'un Modèle de Situation de Travail Pour L'aide À La Formation et À La Simulation Lors de La Conception et L'industrialisation de Systèmes." Ecole Centrale de Nantes.

Shahrokhi, M., and A. Bernard. 2009. "A Framework to Develop an Analysis Agent for Evaluating Human Performance in Manufacturing Systems." CIRP Journal of Manufacturing Science and Technology 2: 55-60.

Shahrokhi, M., and A. Bernard. 2010. "A Development in Energy Flow/barrier Analysis." Safety Science 48 (5): 598-606. Accessed September 2, 2013. http://linkinghub.elsevier.com/retrieve/pii/S092575 3510000111.

Sklet, S. 2006. "Safety Barriers: Definition, Classification, and Performance." Journal of Loss Prevention in the Process Industries 19: 494-506.

Sousa, V., N. M. Almeida, and L. A. Dias. 2014. "Risk-Based Management of Occupational Safety and Health in the Construction Industry - Part 1: Background Knowledge." Safety Science 66: 75-86.

Stoop, J. 1990. "Scenarios in the Design Process." Applied Ergonomics 21 (4): 304-310.

Suh, N. P. 1990. The Principles of Design. New York, NY: Oxford University Press.

Suh, N. P. 2001. Axiomatic Design: Advances and Applications. New York: Oxford University Press.

Sun, H., R. Houssin, M. Gardoni, and F. de Bauvrond. 2013. "Integration of User Behaviour and Product Behaviour during the Design Phase: Software for Behavioural Design Approach." International Journal of Industrial Ergonomics 43 (1): 100-114. doi:10.1016/j.ergon.2012.11.009. 
Tomiyama, T., P. Gu, Y. Jin, D. Lutters, Ch. Kind, and F. Kimura. 2009. “Design Methodologies: Industrial and Educational Applications." CIRP Annals - Manufacturing Technology 58: 543-565.

Village, J., M. Greig, and P. Neumann. 2011. "Adapting the Failure Modes Effect Analysis (FMEA) for Early Detection of Human Factors Concerns." Paper presented at the 42nd Annual Conference of the Association of Canadian Ergonomists, London, Ontario, October 17-20.

Wixson, J. R. 1999. "Function Analysis and Decomposistion Using Function Analysis Systems Technique." Citesser. http://citeseerx.ist.psu.edu/viewdoc/download?doi=10.1.1.127.4279\&amp $\backslash$ nrep=rep $1 \& a m p \backslash$ ntype $=$ pdf.

Zhang, H.-C., T.-C. Kuo, and H. Lu. 1997. "Environmentally Conscious Design and Manufacturing a State-of-the-Art Survey.pdf." Journal of Manufacturing Systems 16 (5): 397-409. 